\title{
The Possibility of Nucleic Acids to Act as Anti-Viral Therapeutic Agents-A Review
}

\author{
Md. Selim Reza1,2*, Farzana Mim², Mohammad Rezaul Quader ${ }^{3}$, \\ Mohammad Jahidur Rahman Khan', Md. Sabir Hossain'2, Kazi Rasel Uddin², Salina Akter², \\ Sharmin Rahman', Sumon Roy ${ }^{3}$, Md. Abdullah Rumman ${ }^{3}$
}

${ }^{1}$ RT-PCR LAB, Bangabandhu Sheikh Mujib Medical College, Faridpur, Bangladesh

${ }^{2}$ Department of Biochemistry and Molecular Biology, Jahangirnagar University, Dhaka, Bangladesh

${ }^{3}$ Department of Biochemistry, Bangabandhu Sheikh Mujib Medical College, Faridpur, Bangladesh

${ }^{4}$ Department of Microbiology, Shaheed Suhrawardy Medical College, Dhaka, Bangladesh

${ }^{5}$ Department of Pharmacology, Ibrahim Medical College, Dhaka, Bangladesh

Email: *selimrezabmb1849@gmail.com

How to cite this paper: Reza, Md.S., Mim, F., Quader, M.R., Khan, M.J.R., Hossain, Md.S., Uddin, K.R., Akter, S., Rahman, S., Roy, S. and Rumman, Md.A. (2021) The Possibility of Nucleic Acids to Act as Anti-Viral Therapeutic Agents-A Review. Open Journal of Medical Microbiology, 11, 198248.

https://doi.org/10.4236/ojmm.2021.113015

Received: August 19, 2021

Accepted: September 21, 2021

Published: September 24, 2021

Copyright $\odot 2021$ by author(s) and Scientific Research Publishing Inc. This work is licensed under the Creative Commons Attribution International License (CC BY 4.0).

http://creativecommons.org/licenses/by/4.0/ (c) (i) Open Access

\begin{abstract}
For just about 30 years, researchers have considered the likelihood to utilize nucleic acids as antiviral therapeutics. In principle, small single-stranded nucleotide sequence (oligonucleotide) could hybridize to a particular gene or messenger RNA and diminish transcription or translation, respectively, in this manner decreasing the amount of protein that is synthesized. Until now, an incredible number of antisense oligonucleotides, double-stranded oligonucleotides, aptamers, ribozymes, deoxyribozymes, interfering RNAs, chimeric RNA-DNA molecules, antibody genes has been created artificially and applied effectively for comprehension and manipulating biological processes and in clinical preliminaries to treat a variety of diseases. Their versatility and potency make them similarly fit candidates for fighting viral infections. However, troubles with their efficiency, off-target effects, toxicity, delivery, and stability halted the development of nucleic acid-based therapeutics that can be utilized in the clinic. The potential for nucleic acid therapeutic agents is significant and is quite recently beginning to be realized. In this review, we have summarized some of the recent advancements made in the area of nucleic acid based therapeutics and focused on the methods of their delivery and associated challenges.
\end{abstract}

\section{Keywords}

Antisense Oligonucleotides, Aptamers, Ribozymes, Deoxyribozymes, RNA Interference 


\section{Introduction}

The most efficacious method to avoid infection with pathogenic viruses is immunization of individuals with prophylactic vaccines. However, for most viruses such vaccines are not available. Antiviral drugs that block replicating virus in infected individuals are therefore of great importance in the battle against virus infections. Forty years ago, Zamecnik and Stephenson proposed the therapeutic use of antisense oligonucleotides on the basis of their finding that Rous sarcoma virus (RSV) replication could be inhibited by a synthetic oligonucleotide complimentary to the RSV genome. This concept opened up a new approach to drug discovery, namely an oligonucleotide binding sequence-specifically via WatsonCrick base-pairing to a complementary target RNA [1]. Since then, continuous progress has been made towards realizing the potential of this novel scientific approach.

While the underlying concept of antisense is very simple, a rigorous understanding of the chemistry of nucleic acids had to be developed for its use in humans. However, the development of antisense-based therapeutics stuttered and almost came to a stop because of problems with toxicity of the oligonucleotides, their instability in serum, and the problem of delivery to the right target cells. A new generation of nucleic acid-based antiviral compounds was subsequently developed, such as ribozymes, deoxyribozymes, aptamers and antibody genes, but they faced similar problems. Some of the problems could be solved using chemically modified nucleic acids instead of normal DNA/RNA oligonucleotides [2]. New hope for nucleic acid-based therapeutics came in 2001 when Elbashir et al. showed that synthetic small interfering RNAs (siRNAs) induced sequence-specific knock-down of genes in mammalian cells without triggering the interferon response. RNAi was immediately recognized as a potentially powerful new tool to combat a variety of viruses [3]. In addition, synthetic siRNAs are also subject to degradation in vivo by nuclease activity [4]. Besides side effects and instability, the efficient and specific delivery of the RNAi inducers to the target cell still requires optimization.

The greatest impediment to the development of nucleic acid-based therapeutic agents is the difficulty in delivering these agents to their target tissue(s). Viral and nonviral systems have been developed for the delivery of therapeutic genes. Viral vectors take advantage of the ability of a virus to penetrate a specific cell, protect the DNA from degradation, and direct it to the cell nucleus. Packaging cell lines for some viral systems ensure that virtually no infectious viruses are present in a sample of vector viruses, although some safety concerns exist in regard to the use of these vectors. Nonviral gene delivery systems include intravenous injection; local injection at the site of the pathology; packaging the nucleic acid into cationic liposomes; physical methods, like electroporation, sonoporation, or hydrodynamic pressure; and conjugating the nucleic acid to another molecule, such as a lipid molecule, cholesterol, collagen, an antibody fragment, or an aptamer. In addition, human artificial chromosomes (HACs) may find use as vec- 
tors for the long-term maintenance and expression of therapeutic genes in human cells [5]. Although all these strategies have problems of instability in vivo due to the nuclease activity and efficient delivery to the specific target cells, recent advancements have been made to overcome such problems by optimizations. The efficacy of the nucleic acid-based molecules is dependent on their expression, stability, and accessibility to the target sites. If properly designed and modified, all these nucleic acids may have significant inhibitory effect on relevant target but combination of more than one type of therapeutic can always show synergistic effect against the virus propagation in host cells. This review summarizes the present status of nucleic acid-based antiviral therapeutics and challenges in their delivery, especially in the context of respiratory viral infections.

\section{Viruses: Essentials of Their Replication and Susceptibility to Nucleic Acid-Based Therapeutics}

Viruses constitute the simplest and most abundant life form. Replication of viruses is largely dependent on delivery of their genomes to host cells and then usurping functions of target cells to produce proteins that are required to form viral progeny (Figure 1) [6]. The mechanisms by which viruses appropriate cellular functions predictably involve some disruption, which is responsible for induction of disease in virus-infected individuals. In addition to viral proteins, host factors are also required to facilitate replication of viruses [7].

Typically, nucleic acids-based antiviral therapeutics aims to deploy DNA or RNA to achieve a therapeutic effect by inhibiting the expression of viral or host factor genes. Capacity of viruses to bypass dependence on host factors is highly constrained; therefore, inhibiting the function of host factors is useful to suppress emergence of escape by the pathogens. When using this approach, appropriate target selection is important. If targeted host factors have important cellular functions, then their silencing may cause toxicity. Another method of providing a high barrier to viral infection is through simultaneous inhibition of multiple viral targets using combinatorial approaches. In addition to direct targeting of viral genes and host factors, gene transfer for immune-based treatment and prophylaxis has potential for countering many viruses. Advances in antiviral gene therapy have been made through steady accumulation of knowledge and as a result of significant breakthrough discoveries (Figure 2). Two momentous advances in the field have been development of technologies based on gene editing and harnessing the naturally occurring RNA interference (RNAi) pathway. Other effective methods of inhibiting viral gene expression included use of antisense oligonucleotides, aptamers and RNase P substrates [8].

\section{Antiviral Nucleic Acid-Based Therapeutics}

Nucleic acid therapeutics are based on nucleic acids or closely related chemical compounds. These can be subdivided into three main groups according to their target molecule. 


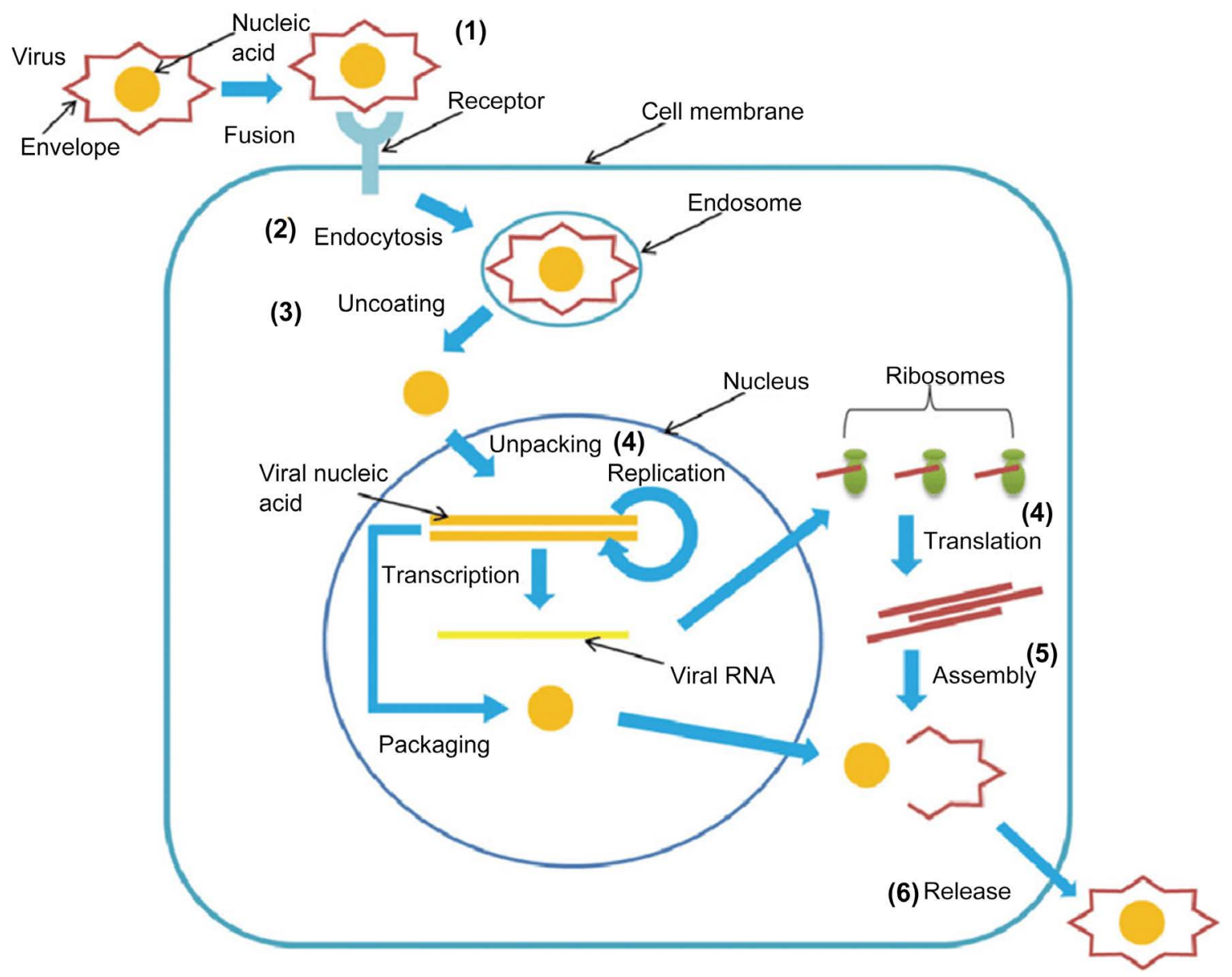

Figure 1. Virus life cycle and possible antiviral mechanism. (1) Attachment: In this step, the viral envelope glycoproteins attach to certain host cell membrane receptors. The potential mechanism of nucleic acids therapeutics are suppression of expression of the viral co-receptor and other host factors (2) Endocytosis: Here, the viral contents are taken up by the host cell. (3) Uncoating: Degradation of the viral capsid by host cell enzymes. (4) Growth: It involves translation and replication of the viral genes. Anti-viral mechanisms are mutation of viral DNA and inhibit their replication, post-transcriptional gene silencing, and transcriptional silencing of viral genes. (5) Assembly: The viral proteins assemble to enclose the viral genome. (6) Release: The mature virus particles escape from the host cell by budding/lysis. In RNA viruses, however, the viral genome is usually not integrated into the host genome, and hence, their RNA molecules are directly used as mRNAs for translation.

1) Targeting viral or cellular nucleic acids: Antisense oligonucleotides, ribozymes, microRNAs (miRNAs) inhibitors, short interfering RNAs (siRNAs), and short interfering DNAs (siDNAs) consist of 15 to 25 nucleotides, which are complementary or partially complementary to their messenger RNA and interact by Watson-Crick base pairing with viral or cellular transcripts leading to their degradation or functional blockage.

2) Targeting viral proteins: Decoys, which are derived from nucleic acid sequences of protein ligands, and short oligonucleotides. Decoys are designed to inhibit the activity of the target protein through high-affinity binding.

3) Targeting viral nucleic acids or viral proteins: Aptamers with a defined tertiary structure that can be selected against highly structured viral nucleic acids as well as viral proteins. 


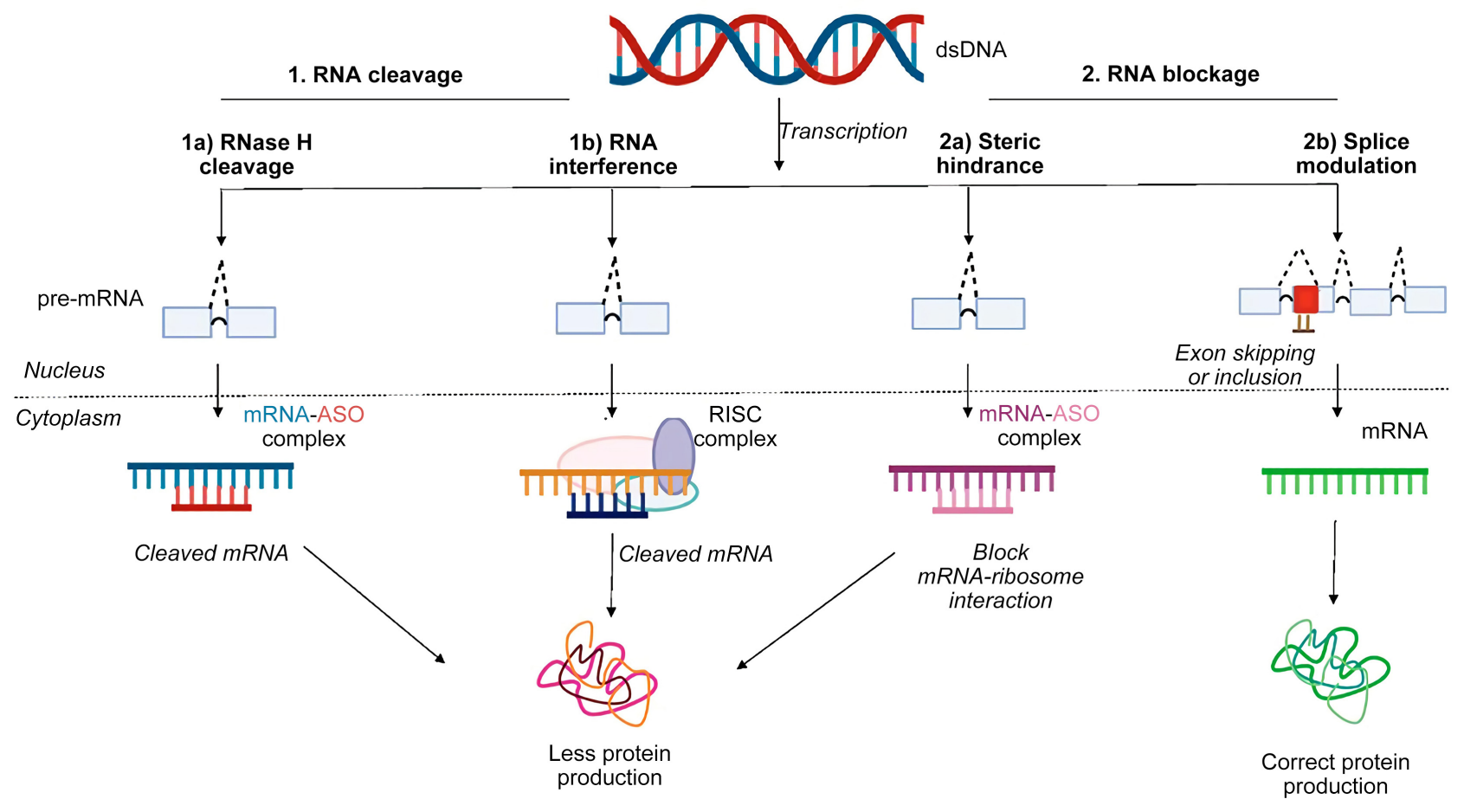

Figure 2. Mechanism of action of antisense oligonucleotides (ASOs). ASOs act by either causing (1) RNA cleavage or (2) RNA blockage. (1a) RNase H1 mediated cleavage, (1b) RNA interference (RNAi), (2a) Steric hindrance, and (2b) Splice modulation.

\subsection{Classes of Antiviral Nucleic Acid-Based Therapeutics Targeting Viral or Cellular Nucleic Acids}

\subsubsection{Antisense Oligonucleotide}

An antisense oligonucleotide may bind to its target nucleic acid either by Watson-Crick base pairing or Hoogsteen base pairing. In Watson-Crick base pairing, heterocyclic bases of an antisense oligonucleotides form hydrogen bonds with the heterocyclic bases of target single-stranded nucleic acids (RNA or singlestranded DNA), whereas in Hoogsteen base pairing, the heterocyclic bases of target are double-stranded nucleic acids. Both these models of binding by antisense oligonucleotides have the potential to regulate gene expression. Antisense oligonucleotides are an attractive potential alternative to conventional drugs as antiviral agents. A major advantage is the relatively simple rational design of oligonucleotides which should bind only to specific nucleic acid sequences, compared with conventional drugs which are frequently targeted against sites of unknown structure in proteins. Progress to date provides hope for the development of a new class of antiviral chemotherapeutics based on antisense oligonucleotides (Figure 3) [9].

\section{Chemical modifications of antisense oligonucleotide}

Although antisense technology can induce profound sequence-specific inhibition of gene expression in some settings, major problems include instability, delivery, and unwanted side effects of the oligonucleotides. Chemical modification of the oligonucleotides was found to improve the efficacy. These modifications affect one of the three main components of nucleotides: the bases, the sugar 


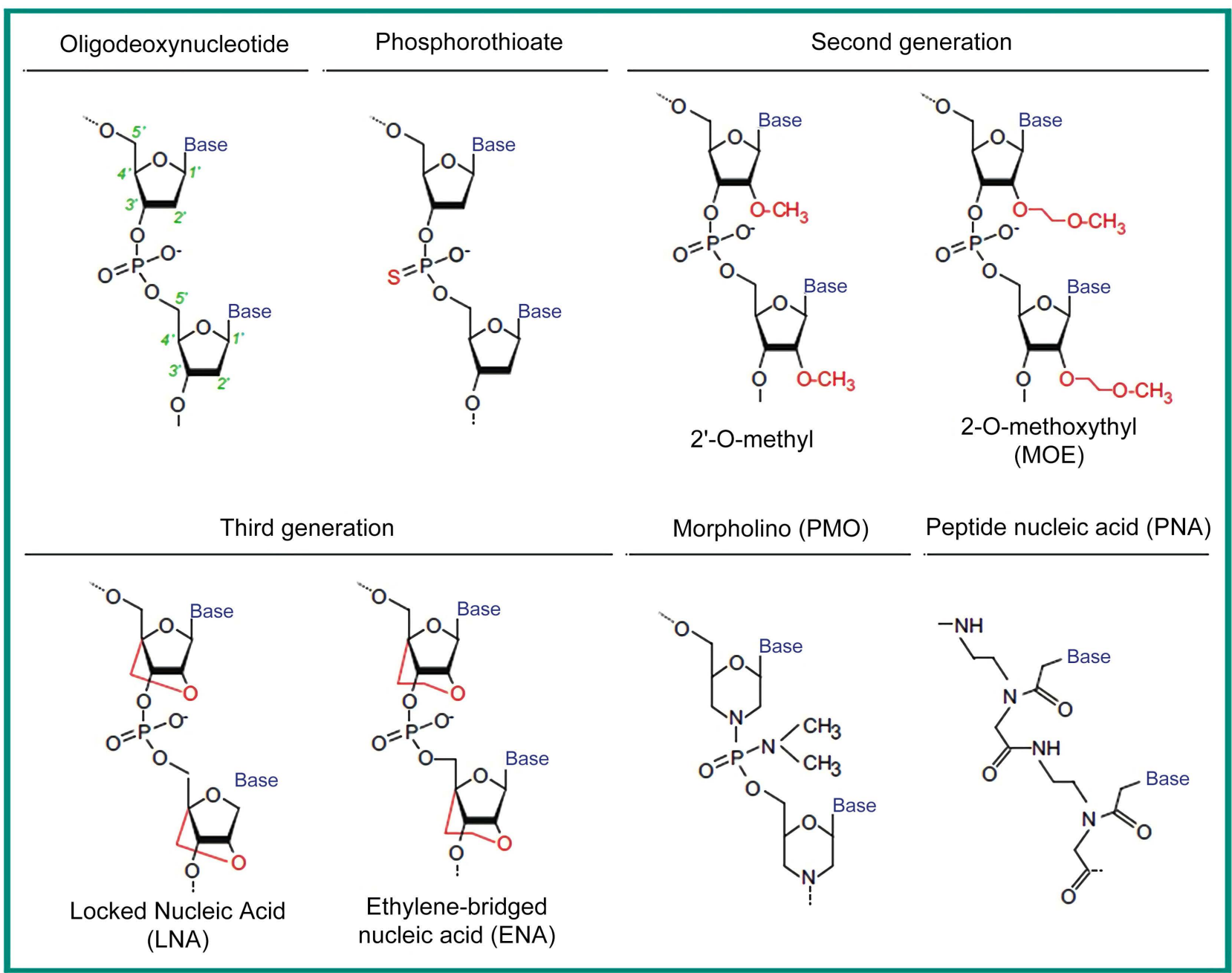

Figure 3. Chemical structures of backbone modifications used in therapeutic nucleic acid analogs.

(especially at the 2' position of the ribose) or the phosphate backbone. Evaluations of some of these modifications, summarized as three "generations" of antisense oligonucleotides.

In first-generation modified oligonucleotides, one non-bonding oxygen atom in the phosphate group is substituted by a sulfur atom (phosphorothioate oligodeoxynucleotides). This modification confers higher stability to the molecules and thus increases their half-life. The advantage of the phosphorothioate-modified oligonucleotides is that it allows RNase $\mathrm{H}$ cleavage of the target sequence. A disadvantage is that the phosphorothioate modification introduces a negative charge that causes nonspecific interactions with other molecules, for example, cellular proteins. As a result, phosphorothioate-modified oligonucleotides are notorious for inducing severe side effects that are toxic for cells [10]. A second generation of modified oligonucleotides was obtained by the introduction of an alkyl group in the 2 ' position of the ribose molecule of nucleotides. The generated molecules include 2'-O-methyl- and 2'-O-methoxyethyl-RNA. These molecular species are less toxic than phosphorothioate oligodeoxynucleotides [11]. The conformation 
changes induced by these modifications and, in particular, the presence of ribose, improve target binding, however they also abrogate the oligonucleotide: target mRNA duplex ability to activate RNase $\mathrm{H}$, a crucial aspect of ASO activity. Thus, the inhibitory effect of these molecules is only exerted through the inhibition of mRNA translation and is thus lower than that of phosphorothioates. This drawback can be avoided by generating chimeric oligonucleotides with 2'-modified nucleotides placed only at the ends of the oligonucleotide, thereby leaving a central RNase-compatible DNA gap. These hybrid oligonucleotides are known as gapmers [12]. Third generation oligonucleotides are DNA and RNA analogues with extensive modifications of the phosphate backbone and the sugar ring. Examples are peptide nucleic acids (PNA), in which the backbone has been replaced by a peptide linker, morpholino phosphoroamidates (MF), and locked nucleic acids (LNA). These modifications provide further improved nuclease resistance and target affinity. In addition, the PNA and MF modifications allow enhanced cellular uptake. To combine all benefits, third generation modifications can be used in combination with unmodified residues in chimaeric gapmers [13] [14].

\section{1) Antisense oligoribonucleotide}

Antisense RNA-mediated gene inhibition is a widely used strategy not only for studying gene regulation and revealing gene function, but also for targeting disease states, especially cancer and viral infection. Antisense RNA has proven a potent inhibitor of gene expression and has the potential to inhibit retroviral replication at a number of stages in the virus life cycle by targeting both viral and cellular RNA sequences. To be an effective therapeutic agent, an antisense RNA must bind to a specified mRNA and prevent translation of the protein (Figure 4) [15].

The possibility of using an expression vector to produce an antisense RNA that suppresses a pathogenic condition has been examined. For example, antisense RNA complementary to three target regions in the 5 ' leader/LTR of human immunodeficiency virus type-1 (HIV-1), the TAR region, the primer binding site and the splice donor $(\mathrm{SD})$-packaging signal $(\Psi)$ region were stably expressed from the CMV IE promoter in Jurkat cells, and expression confirmed by RT-PCR. When challenged with HIV-1, cell lines expressing antisense RNA targeting the $\mathrm{SD} / \Psi$ region showed significant inhibition of replication. These results suggest that the packaging signal $(\Psi)$ of HIV-1 represents an attractive target for antisense RNA-based gene therapy, although the main mode of action of such molecules may well be through antisense effects at an earlier stage of replication than packaging [16].

Hepatitis B virus (HBV) is an infectious agent with about 200 million carriers worldwide. Many patients with HBV infection develop chronic hepatitis, cirrhosis and hepatocellular carcinoma (HCC). Unfortunately, treatment for chronic infection by this virus is far from satisfactory. Oligodeoxynucleotides can only temporarily suppress the pathogenic effect of integrated virus unless given continually, 


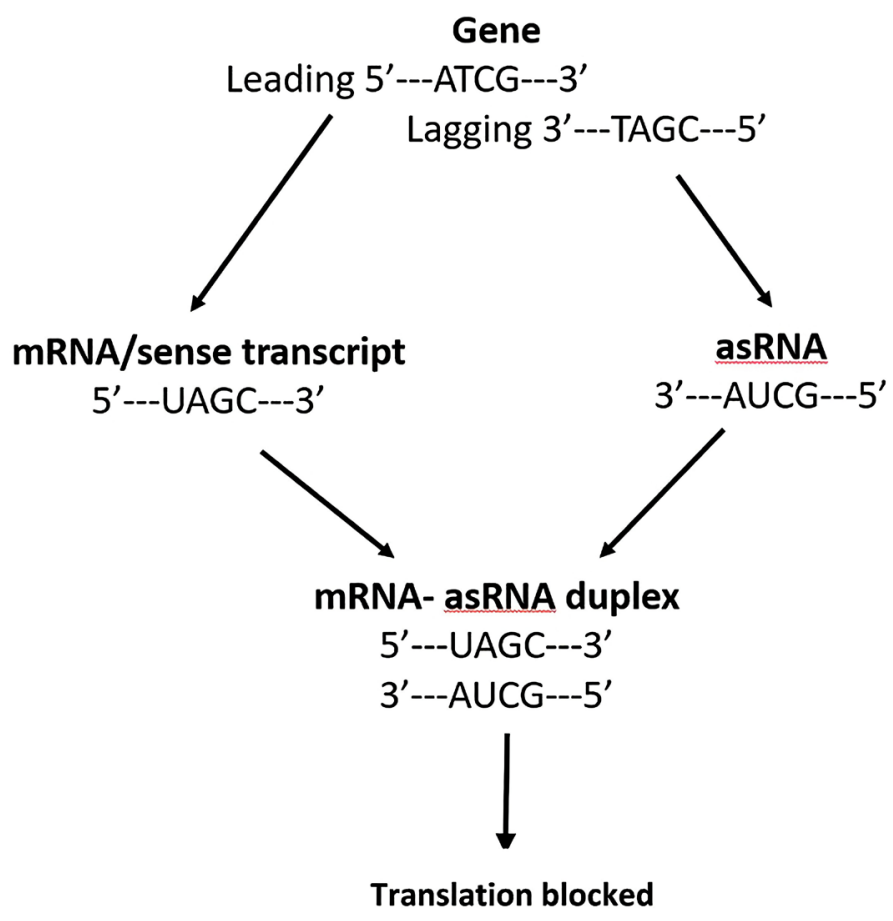

Figure 4. Mechanism of action of antisense RNA. To be an effective therapeutic agent, an antisense RNA must bind to a specified mRNA and prevent translation of the protein.

whereas antisense RNA can be constitutively expressed in a stably transfected cell line, and thus, potentially provide long term protection against the pathogenic effect of integrated virus. Antisense RNAs derived from the HBV genome are promising candidates as antiviral agents and may serve as novel tools to identify functionally important regions of HBV transcripts. Antisense RNAs targeted to the HBsAg coding region can specifically inhibit envelope protein synthesis both in an in vitro translation system, and more importantly, in an HBsAg secreting cell line. The effects were long lasting, and remained demonstrable for more than 10 months post-transfection [17]. Respiratory syncytial virus is a leading cause of respiratory disease in infants, young children, immunocompromized patients, and the elderly. RNase L, an antiviral enzyme of the interferon system, can be recruited to cleave RSVgenomic RNA by attaching tetrameric 2' 5'-linked oligoadenylates to an antisense oligonucleotide complementary to repetitive intergenic sequences within the RSV genome. RBI034, a 2'-O-methyl RNA-modified analogue of the 2 5A anti-RSV compound, was found to have enhanced antiviral activity in cell culture studies while also cleaving RSV genomic RNA in an RNase L- and sequence-specific manner. RBI034s efficacy in suppressing RSV replication in cell culture is 50 to 100 times better than ribavirin, the only approved drug for RSV infection [18].

\section{2) Antisense oligodeoxyribonucleotide}

The antisense oligodeoxyribonucleotides (AODNs) are usually synthetic single stranded DNA oligonucleotides, generally 12 - $30 \mathrm{nt}$ in length, which interact via perfect Watson and Crick base-pairing with the target mRNA. Once intro- 
duced into the cell, pairing of the AODNs with its target blocks ribosomal translation and stimulates degradation of the RNA:DNA hybrid by cellular RNase $\mathrm{H}$ enzymes. Predictably, overexpression of RNase $\mathrm{H}$ amplifies the effect of various AODNs, while conversely inhibiting RNase $\mathrm{H}$ reduces their effect. Certain AODNs are not capable of activation of RNase $\mathrm{H}$; instead they inhibit gene translation by steric competition with the translational machinery. In addition, AODNs can target intron-exon junctions to disrupt splicing (if bound to premRNA). Furthermore, AODNs can also disrupt RNA trafficking by occupying protein-RNA interaction sequences necessary for correct intracellular localization (Figure 5) [19].

AODNs have been widely used to interfere with the gene expression of a number of human viral pathogens, including influenza virus, vesicular stomatitis virus, respiratory syncytial virus (RSV), human papillomavirus (HPV), herpes simplex virus, human immunodeficiency virus (HIV), hepatitis, and others [9]. The first AODN drug approved by the US Food and Drug Administration was Vitravene (Fomivirsen) in 1998, which targets the cytomegalovirus (CMV) IE2 gene for the treatment of CMV induced retinitis. Fomivirsen is a phosphorothioate ASO (first-generation) and binds to the IE2 fragment of mRNA of CMV that is involved in viral replication. Fomivirsen is administered as an intravitreal injection and has been found to have long duration of action; plasma concentrations are negligible. Metabolism of fomivirsen is locally mediated by exonuclease enzyme in the eye. No significant drug interactions have been observed with fomivirsen except that it should not be administered within 4 weeks following administration of the antiretroviral agent cidofovir. The drug is administered intravitreally once a week and the median time for progression of retinitis in patients was found to be 71 - 90 days. No serious adverse drug reactions were observed during clinical trials for intravitreal fomivirsen. Reports of occurrence of reversible bull's-eye maculopathy with fomivirsen administration have been documented without any effect on vision. Following the advent of highly active antiretroviral drugs for treating infections with human immunodeficiency virus, a decline in the rate of CMV retinitis in patients was observed. Hence, fomivirsen was withdrawn by the marketing authorization holder for commercial reasons [20].

An alternative antisense-based antiviral approach relies on a 937 nt RNA molecule complementary to the env gene of HIV. This antisense RNA, called VRX496, is inserted into a HIV-1-based lentiviral vector which retains the long LTRs of HIV, thus its expression is up-regulated upon infection with wild type HIV. When the virus starts to replicate in the host cell, the antisense RNA prevents the production of the envelope protein, thereby blocking the HIV replication cycle. VRX496 is currently being tested in phase II clinical trials [21]. Another promising approach to inhibit HIV was developed by Matzen et al. which is based on an asON complementary to the polypurine tract. The viral RNase $\mathrm{H}$, activated by this asON/viral RNA heteroduplex, cleaves the viral genome and thus destroys it. In the case of positive-strand RNA viruses, such as 

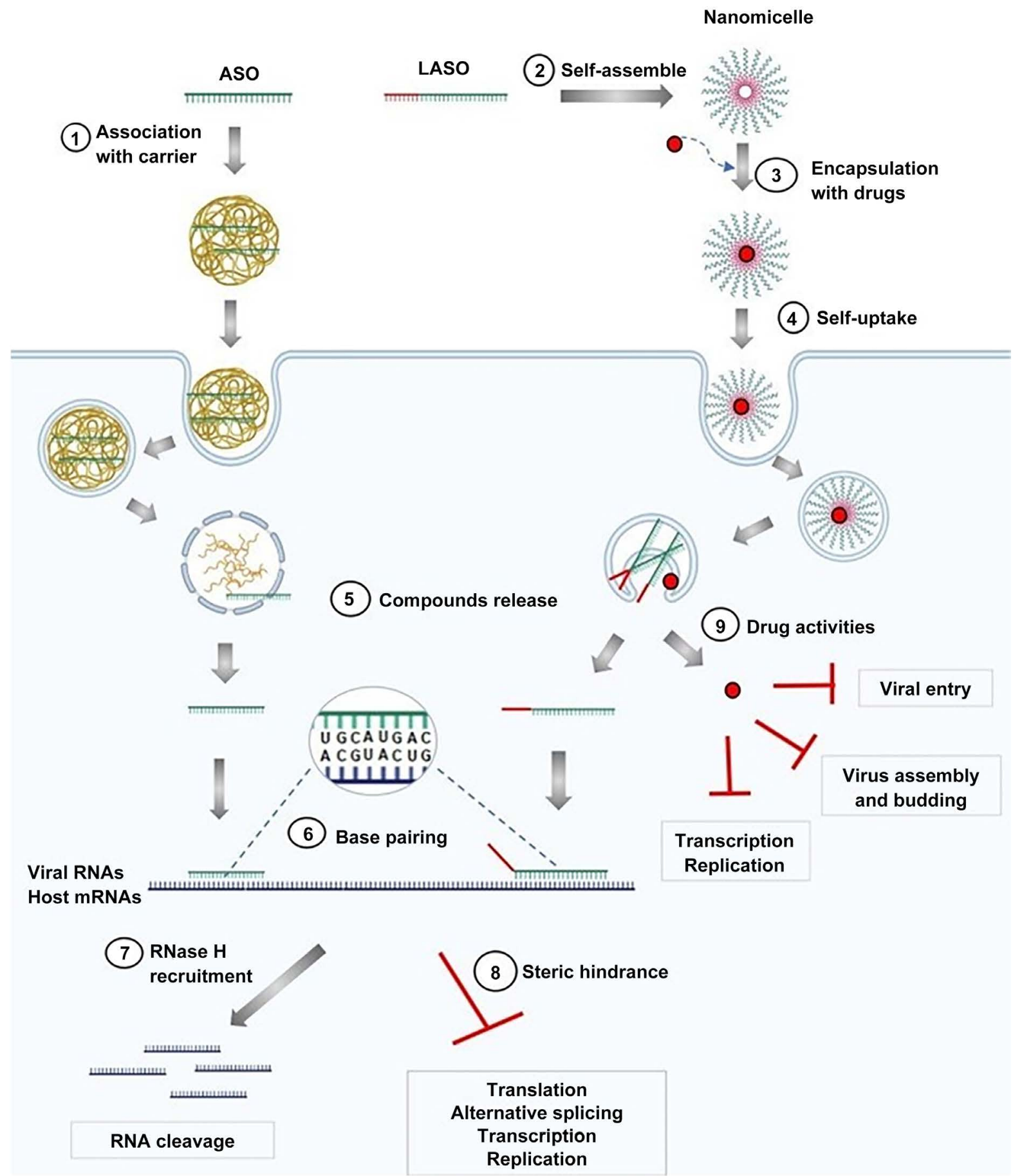

Figure 5. Mechanism of action of antisense oligonucleotides. Association of ASOs with carriers enhances their cellular delivery (1). Alternatively, lipid-modified ASOs (LASO) can self-assemble into nanomicelles (2), which have the ability to encapsulate hydrophobic drugs such as antiviral small molecules (3) and enter the cells unaided (4). Once delivered into the cells, ASOs, LASOs, and drugs can be released (5). ASOs/LASOs base-pair with the target RNA sequences, which could be host cellular mRNA or a viral RNA genome (6). The formed DNA:RNA hybrids can induce cleavage of the RNA in the heteroduplexes (through RNase H recruitment and activity), leading to degradation of the targeted sequences (7). Binding of ASOs/LASOs to the target RNA sequences also can form a steric hindrance blocking translation or modulating alternative splicing, thereby shutting down the gene expression of host genes or disrupting RNA-based viral functions such as translation, replication, and transcription (8). In addition, the conjugated drugs can exert their activities via inhibition of viral processes such as transcription/replication, host entry, and virus assembly and budding. 
HCV, the replication takes place entirely in the cytoplasm of the host cell. Therefore, for those viruses an asON-mediated cleavage of the viral RNA by the nuclear enzyme RNase $\mathrm{H}$ is not possible [21]. ISIS developed a $20 \mathrm{nt}$ PS-modified asON (ISIS-14803) which targets a region within the internal ribosome entry site (IRES) of HCV RNA and acts via a steric block mechanism. ISIS-14803 was tested in clinical trials, but it showed a very low anti-HCV activity in patients, thus studies were discontinued [22]. Recently, Warren et al. described the application of positively charged phosphorodiamidate morpholino-modified asONs in nonhuman primates infected with Zaire Ebola virus (ZEBOV) or Lake Victoria Marburg virus (MARV). The recovery rate of infected monkeys upon treatment with asONs was $60 \%$ and $100 \%$ after infection with ZEBOV and MARV, respectively. These asONs, which will soon be entering phase I clinical trials, sterically hinder the translation of VP24 and VP35 viral transcripts which are important for ZEBOV and MARV replication [23].

\subsubsection{Ribozymes}

Ribozymes are promising tools for the specific inhibition of viral gene expression and replication. They represent one of the most attractive developments of antisense nucleic acids, which have been shown in the past few years to act as antiviral agents. Ribozymes complex with target sequences via complementary antisense sequences and hydrolyze the target site [23]. Ribozymes are single stranded RNA molecules (50 - $100 \mathrm{nt}$ ) having a well-defined tertiary structure allowing them to catalyze chemical reactions without the requirement of any protein. They are naturally occurring molecules originally discovered in Tetrahymena thermophilia by T.R. Cech who was awarded in 1989 the Nobel Prize for Chemistry [24]. Ribozymes catalyze reactions such as hydrolysis of phosphodiester bonds, peptide bond formation, ligation, as well as polymerization and can be subdivided into cis- (intramolecular catalysis) or trans-acting (intermolecular catalysis) molecules [25]. Of the different types of ribozymes, the hammerhead and hairpin ribozyme have been studied extensively (Table 1) [26].

Hammerhead ribozymes are typically $\sim 40 \mathrm{nt}$ long and have a secondary structure formed by three helical domains (domains I, II, and III), surrounding a junction containing the catalytic core, defined by the presence of specific nucleotides (Figure 6(A)) [26]. While helix II is formed intramolecularly by the ribozyme itself, helices I and III depend on pairing of the single-stranded ribozyme sequence with its complementary sequence in the substrate, and can thus be chosen at will to match the sequence of the target RNA [27]. Hairpin ribozymes consist of 4 paired helices (helices I - IV) and two internal loops (Figure 6(B)) [26]. Enzymatic cleavage occurs at the level of a bond in loop A. In the plant satellite RNAs, cleavage takes place within the RNA molecule itself; however the sequences of helices I and II can be modified in order to render them complementary to a desired nucleotide sequence of the target RNA. In contrast to hammerhead ribozymes, hairpin ribozymes do not require the presence of a metal ion in the catalytic core [28]. 
Table 1. Comparison of hammerhead (HH) and hairpin (HP) ribozymes [26].

\begin{tabular}{ccc}
\hline Therapeutic feature & $\mathrm{HH}$ & $\mathrm{HP}$ \\
\hline Size & $30-40 \mathrm{nt}$ & $65+\mathrm{nt}$ \\
{$\left[\mathrm{Mg}^{++}\right]$requirement } & $>10 \mathrm{mM}$ & $<10 \mathrm{mM}$ \\
Chemical synthesis & High yield & Poor yield \\
Chemical modifications & Yes & No \\
$\mathrm{K}_{\mathrm{CAT} / \mathrm{Km}}$ & $>1 \mathrm{~min}^{-1} \cdot \mu \mathrm{M}^{-1}$ & $>1 \mathrm{~min}^{-1} \cdot \mu \mathrm{M}^{-1}$ \\
Nuclease resistance & Poor & Poor \\
Delivery vector & Not required & Required \\
Clinical trials & Yes & Yes \\
Catalytic performance in vivo & Medium/Poor & High \\
\hline
\end{tabular}

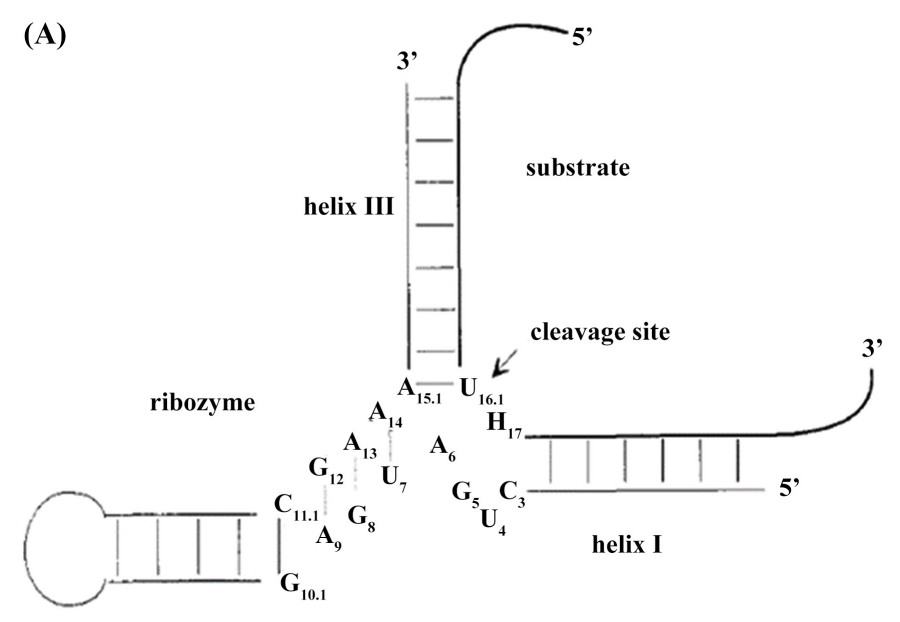

(B)

helix II

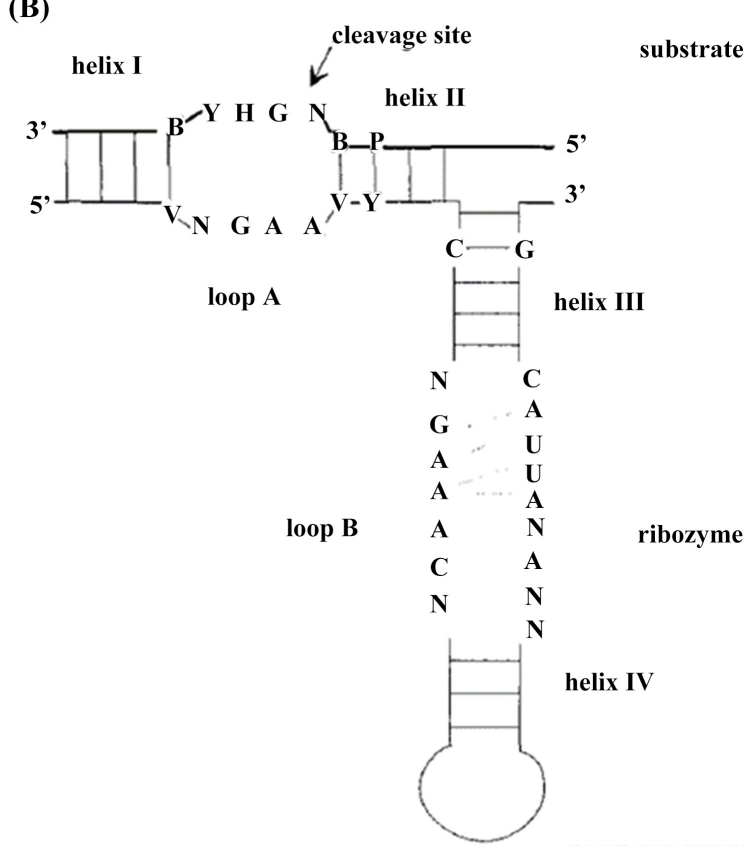

Figure 6. Secondary structure comparison among (A) hammerhead and (B) hairpin ribozymes. Substrate RNA chains have always been indicated using a heavier line, cleavage sites are indicated by an arrow. Degenerate nucleotide positions are indicated using the following codes P, A or G; Y, C or U; B, D, H, V, all other nucleotides except A, C, G, U, respectively; N, any nucleotide.

Generally, reactions mediated by ribozymes are multiple-turnover and sequence-specific, both characteristics make these molecules suited candidates for therapeutic application (Figure 7) [29]. For this purpose, usually trans-cleaving hammerhead ribozymes are used, which are characterized by a central catalytic domain and two flanking arms (6 - $12 \mathrm{nt})$ complementary to the target RNA. To improve stability and affinity for the target, modified nucleotides such as locked nucleic acids (LNA) or 2'-O-methyl (2'-OMe), are commonly introduced into the flanking arms of the ribozyme. Ribozymes can be endogenously transcribed from vectors or chemically synthesized and delivered to cells [30].

For exogenous delivery the ribozyme may be synthesized in vitro or even 


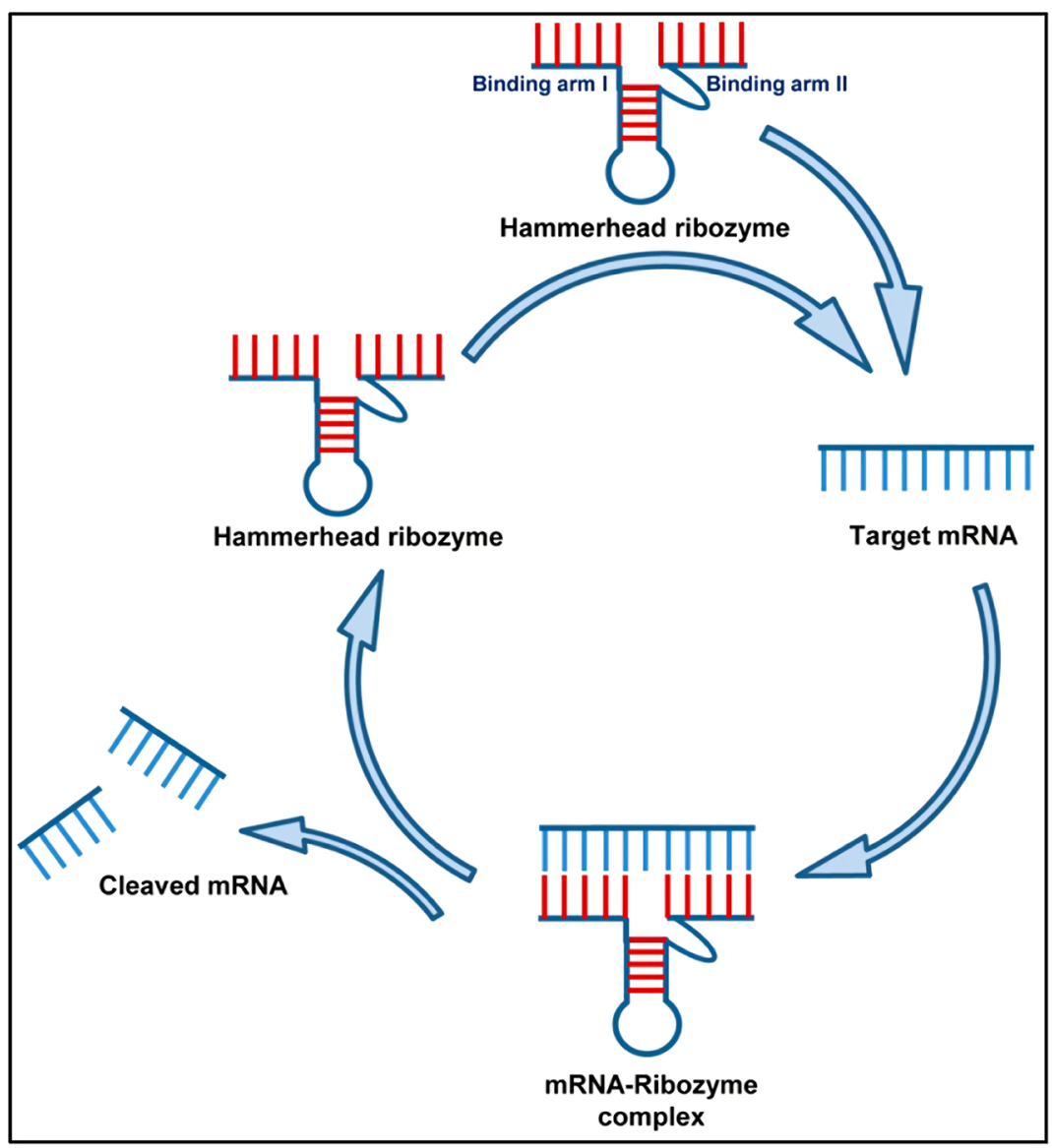

Figure 7. Mechanism of action of Ribozyme. A hammerhead ribozyme has two binding arms designed to bind to the complimentary RNA targets in a Watson-Crick pairing. The ribozyme binds to its target mRNA and makes an mRNA-ribozyme complex. The catalytic motif of the ribozyme then cleaves its target RNA into pieces, thus inhibiting gene expression. After cleaving the RNA target, the ribozyme becomes free again to enter into the next cycle.

chemically, and the resulting RNA then is delivered to the cell by standard transfection methods, e.g., by lipofectamine or electroporation. An exogenous synthesis bears the added possibility of modifying the RNA molecule during or after synthesis in a nonphysiological way, to probe structural modifications at individual positions or to provide an improved resistance against cellular nucleases, and therefore achieve a longer lifetime. Such modifications include substitution of nucleotides by 2'-fluorocytidine in the nonessential parts of the ribozyme, or insertion of phosphorothioate internucleotide bonds. Such modifications will increase the stability of ribozymes against nucleases without serious losses in cleavage activity. After exogenous transfection of such RNAs or RNA variants, the ribozyme-mediated inhibitory effect will inevitably be abolished when the ribozyme itself is finally destroyed in the cellular environment; otherwise it has to be supplied repeatedly. The other way to introduce ribozymes into the cell is by endogenous expression following transfection of a ribozyme-encoding cDNA. From an expression cassette, the ribozyme cDNA will be transcribed repeatedly 
by cellular RNA polymerases. By making the catalytic RNA part of a larger transcript (mostly mRNA or tRNA), it shares the fate of the RNA species in which it is inserted, in its promoter-controlled expression, and also its cellular localization, as well as decay rates. Endogenous expression includes the possibility of inserting a selection marker, e.g., an antibiotic-resistance gene, into the ribozyme-encoding plasmid DNA [31].

Human papillomaviruses (HPV) are double stranded DNA viruses $(8 \mathrm{~kb})$ that infect stratified epithelia (i.e. skin or genital tract). The relationship between cervical cancer and HPV is related to the production of two viral early proteins E6 and E7, which are sufficient and necessary to acquire and maintain a transformed phenotype. Two hammerhead ribozymes were directed to the translational start site of HPV-16 E6 and E7 genes. Both ribozymes (nt 110 and 558) were assayed in vitro and showed efficient cleavage of the target in different conditions of ionic strength, $\left[\mathrm{Mg}^{++}\right]$, and temperature. Evaluation of the simultaneous activity of both ribozymes led to the conclusion of a cooperative effect suggesting a dual use of this ribozyme to disrupt HPV-16 E6/E7 expression [32]. A comprehensive approach on 5'-GUC-3' hairpin ribozyme target sites on HPV16 E6/E7 genes resulted in six different hairpin ribozymes. However, only two ribozymes processed significantly ( $>90 \%)$ the target sequence in vitro. Ribozyme in vivo performance resulted in the cis-inhibition of E6/E7 expression and growth delay and suppression of immortalization on transfected human normal keratinocytes [33].

AIDS and its associated disorders are caused by the human immunodeficiency virus type 1 (HIV-1). The HIV-1 RNA genome (approximately $9.8 \mathrm{~kb}$ ) contains replicative (gag, pol, env), regulatory (tat, rev, tev, vpr, nef) and accessory (vpu, vif) genes [34]. Because the HIV genome is RNA, all of these genes are potential targets for ribozyme therapy. Therefore, there is a wide variety of targets for ribozyme therapy including mRNAs from host cell receptors and viral elements. For the retrovirus HIV-1, a tat-vpr-specific anti-HIV ribozyme, called OZ1, is currently been tested in phase II clinical trials. OZ1 consists of a Moloney murine leukemia virus-based gammaretroviral vector (LNL6) containing a gene that encodes a ribozyme targeting the overlapping vpr and tat reading frames of HIV-1. This approach is based on a gene transfer by which the DNA of the OZ1 retroviral vector is integrated into hematopoietic stem cells. In vitro experiments showed long-term inhibition of HIV-1 replication by OZ1 in cell culture without occurrence of escape mutants. In HIV-infected patients treated with OZ1, the CD4+ lymphocyte counts were higher than in the group treated with placebo. Then again, over time a decline in the percentage of patients who maintained the integrated DNA from the OZ1 retroviral vector was observed [35]. Recently, a very promising hammerhead ribozyme (HHPol13) targeting the HIV-1 pol gene was also described. The antiviral effect of HHPoll3 was compared to the one of an siRNA targeting the same region in the viral pol gene. Results showed that the ribozyme led to a drastic reduction of HIV-1 replication in cell culture experi- 
ments while the siRNA showed no inhibition [36]. The Hepatitis B Virus (HBV) is a $3.2 \mathrm{~kb}$ double-stranded DNA virus from the family hepadnaviridae. HBV X protein $(\mathrm{HBx})$ is a transcriptional activator required for the establishment of HBV infection and implicated in hepatocarcinogenesis. The specific repression of HBx gene expression may be a good strategy to block the progression of liver diseases caused by HBV infection. Two ribozymes targeting HBV Surface and X transcripts were designed to cleave 3 ' to nt 476 and 1649, respectively. The ribozyme target sites were selected on the basis that they were highly conserved amongst different viral isolates, they contained the 5'-GUC-3' triplet preferred by $\mathrm{HH}$ ribozymes and were present in multiple transcripts. Ribozyme treatment caused a marked reduction in Surface mRNA compared to untransduced cells [37]. The HBV encapsidation signal $(\varepsilon)$ is a highly conserved cis-element present twice on the HBV RNA. Effective in vitro cleavage inside $\varepsilon$ has been achieved by hammerhead ribozymes containing flanking sequences complementary to an adjacent less structured region suggesting a potential target for in vivo ribozyme therapy [38].

The hepatitis C virus (HCV) is an enveloped positive sense RNA virus. A ribozyme, called Heptazyme targeting the highly conserved IRES in the 5'-untranslated region (5'-UTR) of the HCV genome, was tested in Phase II clinical trials. Heptazyme led to a $10 \%$ reduction of the viral load in the serum of patients. However, toxicological tests for this ribozyme were not encouraging and led to discontinuation of the clinical studies [39]. Most recently, Levesque et al. coupled anti-HCV ribozymes with a specific on/off adaptor, called SOFA, which enable cleavage activity only in the presence of the desired RNA substrate increasing the selectivity of the ribozymes. They examined in vitro the ability of SOFA-coupled ribozymes to inhibit HCV replication using a luciferase-based replicon and observed up to $40 \%$ reduction in the luciferase activity [40].

\subsubsection{Deoxyribozymes}

A non-natural variant of ribozymes are the so-called deoxyribozymes or DNAzymes, in which the nucleic acid is DNA instead of RNA (Figure 8). Similar to ribozymes, the molecules also consist of a catalytic domain flanked by sequences pairing with the target RNA [41]. The discovery of these molecules has offered an answer to some of the limits of conventional ribozymes. First, deoxyribozymes, being made of DNA, are easier and less expensive to synthesise, while DNA is much more resistant than RNA to degradation both in vitro and in vivo. In fact, studies have shown that, in contrast to ribozymes, very stable deoxyribozyme constructs can be created via the introduction of a minimal number of modifications, reducing the possibility of nonspecific toxic effects. Another intrinsic advantage of deoxyribozymes lies in the fact that a DNA:RNA duplex tends to dissociate more easily than an RNA:RNA duplex; thus, when dealing with long-sequence targets, a deoxyribozyme should be more active-under multiple-turnover conditions-and potentially more selective than a traditional ribozyme (Figure 9) [29]. The superior chemical stability, lower potential toxicity, 


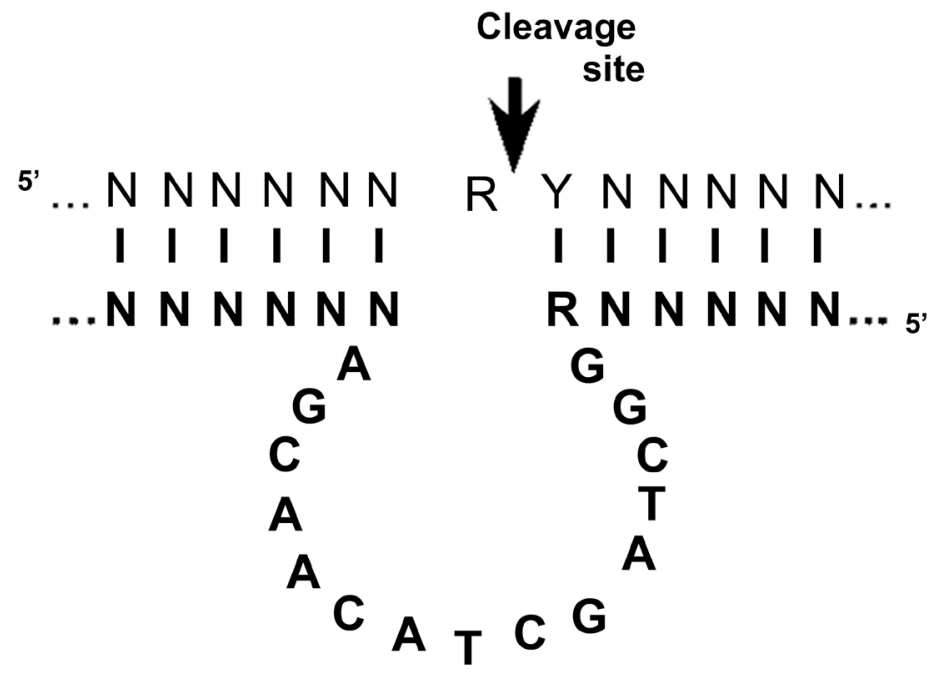

Figure 8. Secondary structures of the 10 - 23 deoxyribozymes, with bound substrate. The DNA enzymes are shown in bold and their RNA substrates in thin letters. $\mathrm{N}$ represents any nucleotide, while $\mathrm{R}$ indicates a purine and $\mathrm{Y}$ a pyrimidine.

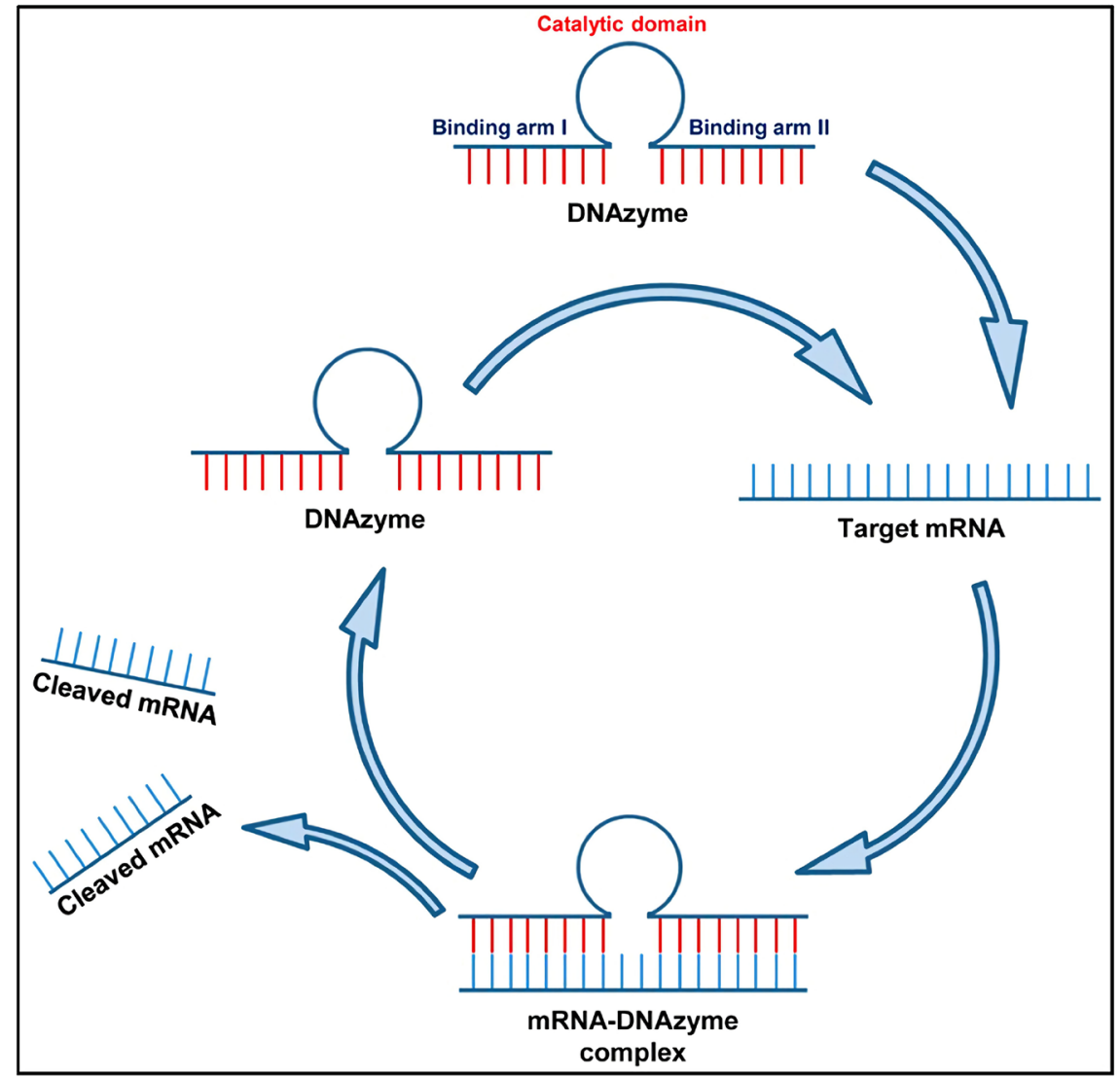

Figure 9. Mechanism of action of DNAzyme. A DNAzyme has two binding arms designed to bind to the complimentary RNA targets in a Watson-Crick pairing. The DNAzyme binds to its target mRNA and makes an mRNA-DNAzyme complex.

and improved catalytic efficiency make deoxyribozymes substantially more attractive than ribozymes as candidates for exogenous applications. However, a 
deoxyribozyme cannot be produced continuously after the vector that encodes it is introduced into a particular tissue, because only ribozymes are produced from the DNA sequence. Therefore, deoxyribozymes must be delivered directly to affected cells [42] [43].

Deoxyribozymes can be considered as promising antiviral agents due to their ability to efficiently cleave RNA molecules with high specificity. Several studies have shown the usage of DNAzymes to inhibit influenza A and B virus replication in host cells. DNAzymes have also been shown to inhibit the replication of SARS coronavirus (SARS-CoV), Respiratory syncytial virus (RSV), human rhinovirus 14 and HCV. Influenza A virus genome segment 7 encodes protein M1, which is the matrix protein playing crucial role in the virus life cycle. In a study, several novel 10 - 23 DNAzymes and hammerhead ribozymes, specifically targeted to cleave at the conserved domains of the influenza virus M1 RNA are used. The $\mathrm{Mg}^{2+}$-dependent sequence-specific cleavage of M1 RNA was achieved by both the DNAzymes and hammerhead ribozymes in a dose-dependent manner. This combination of catalytic DNAzymes and hammerhead ribozymes with antisense molecules, in principle, resulted in more effective gene suppression, inhibited the whole virus replication in host cell, and thus could be exploited for therapeutic purposes [44].

The BM2 ion channel protein of influenza B virus is highly conserved and is essentially required during the uncoating processes of virus, thus an attractive target for designing antiviral drugs. A group screened several DNAzymes containing the 10 - 23 catalytic motif against the influenza B virus BM2 RNA. DNAzymes directed against the predicted single-stranded bulge regions showed sequence-specific cleavage activities. The DNAzyme209 not only showed significant intracellular reduction of BM2 gene expression in transient-expression system but also provided considerable protection against influenza B virus challenge in MDCK cells [44].

RSV has also been targeted using DNAzymes. A series of Dzs were designed and synthesized to silence RSV N, M2 and F genes. One Dz (DZn1133) cleaved the RSV RNA in vitro, inhibited the transcription and expression of $\mathrm{F}$ viral gene, reduced the RSV production by about 7 logs and protected more than $90 \%$ of RSV-infected Hep-2 cells from the cytopathic effect when used at the concentration of $8 \mu \mathrm{M}$. Additionally, 10 wild RSV strains (including both subgroups A and B) isolated from patients showed significant suppression by DZn1133 with higher anti-RSV activity than that for ribavirin (1- $\beta$-D-ribofuranosyl-1-H-1,2,4-triazole3 -carboxamide) or an antisense oligonucleotide (ODN) complementary to the same region of the N RNA [45].

SARS-CoV has also been targeted using DNAzyme molecules. The use of a DNAzyme to target the 5'-UTR of a highly conserved fragment in the SARS-CoV genome to suppress viral replication has been reported. A study showed the efficacy of a mono-DNA enzyme (Dz-104) possessing the 10 - 23 catalytic motif, both in vitro and in cell culture experiments. The Dz-104 showed an in vitro cleavage of the SARS-CoV RNA substrate and reduced the expression of the 
SARS-CoV 5'UTR-eGFP fusion RNA in the mammalian cells. The results provide a basis for the potential therapeutic usage of DNA enzymes to combat SARS infection [46].

\subsubsection{Chimeric RNA-DNA Molecules}

A chimeric RNA/DNA oligonucleotide (chimeraplasts) was developed to correct point or frameshift mutations in episomal or chromosomal copies of genes. It consists of 68 nucleotides (nt) that base-pair to give a double-stranded molecule, in which one strand is comprised entirely of DNA, and the other strand comprises of two runs of $10 \mathrm{nt}$ of 2'-O-methyl (2'-O-Me) RNA, separated by a $5 \mathrm{nt}$ stretch of DNA (Figure 10(A)) [47]. A short region predicted to have a high

\section{(A)}

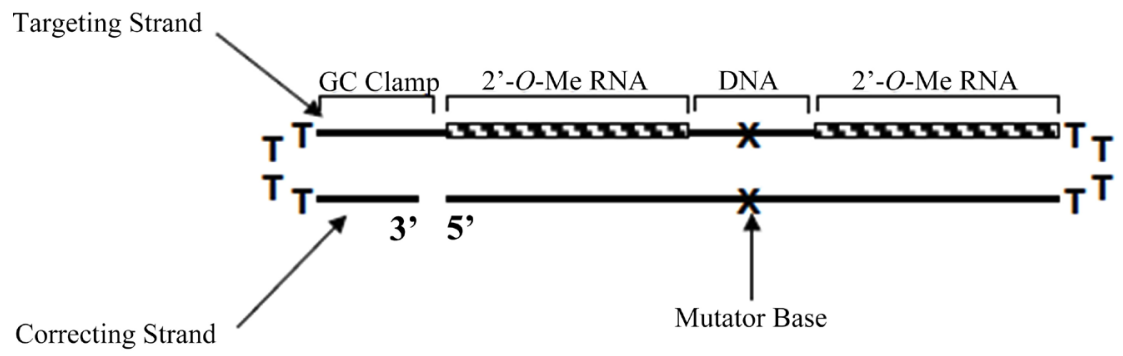

(B) Genomic DNA
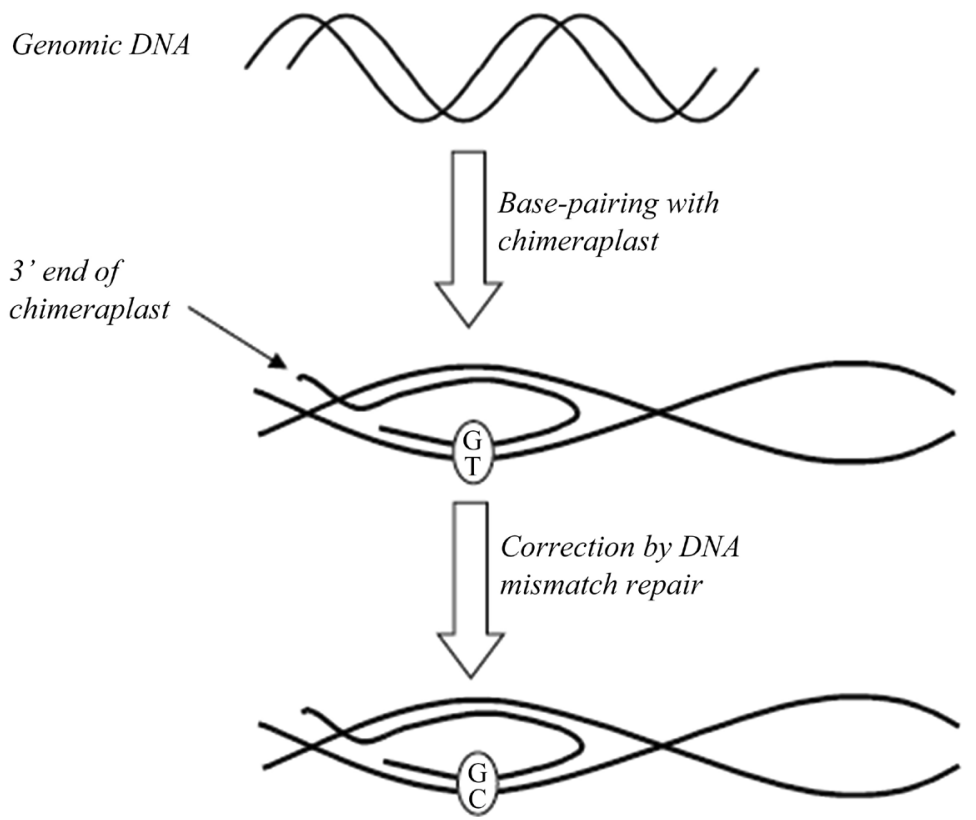

Figure 10. (A) The structure of a typical chimeraplast, in which the chimeric (targeting) strand is entirely base-paired to the all-DNA (correcting) strand. (B) Schematic representation of chimeraplast action. Strand invasion by the chimeraplast is initiated by RecA, and stabilised by base pairing of the targeting strand to the upper strand of the genomic DNA. The base pairing of the correcting strand to the lower strand of the genomic DNA creates a mismatch, which is repaired. This example depicts a $\mathrm{T}$ to $\mathrm{C}$ mutation. 
melting temperature (a GC clamp) is located at the 3' end, and four T residues separate the double-stranded regions, allowing the energetically favourable formation of tight hairpins. The base that is to be mutated lies at the centre of the stretch of five DNA nucleotides on the chimeric strand, and has its complement at the centre of the all DNA strand. This ensures that the chimeraplast is capable of intramolecular base pairing along its entire length (Figure 10(B)) [47]. It is presumed that invasion of the host genome is initiated and stabilised by the chimeric strand; the Tm of a hybrid between DNA and 2'-O-Me RNA is higher than that of either DNA-DNA or DNA-RNA, and will thus be more stable [48].

Severe acute respiratory syndrome (SARS) is a severe pulmonary infectious disease caused by a novel coronavirus. To develop an effective and specific medicine targeting the SARS-coronavirus (CoV), a chimeric DNA-RNA hammerhead ribozyme was designed and synthesized using a sequence homologous with the mouse hepatitis virus (MHV). The synthetic ribozyme cleaved the synthetic target MHV and SARS-CoV RNA into fragments of predicted length. The chimeric DNA-RNA hammerhead ribozyme targeting SARS-CoV significantly inhibited multiplication of MHV in DBT cells by about $60 \%$. The chimeric DNARNA hammerhead ribozyme targeting SARS-CoV significantly inhibited the expression of SARS-CoV RNA in 3T3 cells transfected with the recombinant plasmid. The chimeric DNA-RNA ribozyme targeting SARS-CoV significantly inhibited MHV viral activity and expression of recombinant SARS RNA in vitro. These findings indicate that the synthetic chimeric DNA-RNA ribozyme could provide a feasible treatment for SARS [49].

\subsubsection{Interfering RNAs and Their Application to Viral Infection}

RNA interference (RNAi), an ancient defense pathway, is a posttranscriptional mechanism of gene silencing through chromatin remodeling, inhibition of protein translation, or direct mRNA degradation. RNAi is a naturally occurring process of gene regulation present in plants and mammalian cells. This phenomenon was first observed in plants in the late 1980s, but its molecular mechanism remained unclear until it was discovered in 1998 by Fire et al., in the nematode $C$. elegans [50]. The process is triggered by the presence, in the cytoplasm, of small, double-stranded RNA (dsRNA) molecules of $21-26 \mathrm{bp}$, with two unpaired bases at the 3' ends and phosphorylated 5' ends. One strand of these dsRNA molecules (the guide strand) is assembled into a ribonucleoprotein complex called RISC (RNA-induced silencing complex), which selectively binds a target RNA, inducing its cleavage or blocking its translation. By pairing with the target mRNA, the guide strand confers binding specificity to RISC. The dsRNA molecules that activate RNAi can be generated by one of at least three pathways: the microRNA (miRNA), the short interfering RNA (siRNA) and short hairpin RNA (shRNA), also called expressed RNAi activator pathways [51].

\section{1) MicroRNAs}

MicroRNAs (miRNAs) are noncoding RNA molecules of 18 - 25 nucleotide in length that regulate at posttranscriptional level the expression of genes by bind- 
ing to the 3'-UTR of target genes. A miRNA can regulate different mRNAs, because they are not specific to a single mRNA. They are generated by the cells from specific RNA transcripts forming stem-loop structures (i.e., palindromic regions interrupted by a loop of non-complementary nucleotides). The genes coding for these transcripts are localized within introns of protein-coding genes ( $40 \%$ of cases) or in intergenic regions ( $60 \%$ of cases); in the latter situation, the same genomic region often contains a cluster of different miRNA genes, one close to the other. Most miRNA genes are transcribed by RNA polymerase II as long (in some cases, over $1000 \mathrm{nt}$ ) RNA transcripts. These transcripts, known as primary miRNA (pri-miRNA), contain a CAP and a poly-A at their 5' and 3' ends respectively [52]. They are processed in the nucleus by a complex consisting of at least two components: the RNase III enzyme Drosha and a dsRNAbinding protein called Pasha in Drosophila or DGCR8 (DiGeorge critical region 8) in mammals. This complex, also known as the Microprocessor, processes the pri-miRNA to generate the pre-miRNAs, which consists of a short stem-loop structure of $65-75 \mathrm{nt}$. These are transported from the nucleus to the cytoplasm by exportin-5, and here are further processed by a complex of proteins that includes the RNase III Dicer and the protein Loquacious (Loqs) in Drosophila or TRBP in humans to generate the final miRNAs, presenting two characteristic overhang nucleotides at their 3' ends. Processing by Dicer is coupled with loading of the guide strand into RISC, which is the final effector of RNAi [52].

\section{2) Short interfering RNAs}

Short Interfering RNAs (siRNAs) are short double-stranded RNA segments with $21-23$ nucleotides and are completely complementary to the mRNA sequence of the protein whose transcription is to be blocked. Unlike miRNAs, siRNAs are generated from longer precursor dsRNAs, which can be endogenously introduced into the cells or produced endogenously. Similar to miRNAs, these dsRNA molecules are also processed by Dicer and the final, RISC-mediated RNAi pathway is in common with that of miRNAs [53]. The main advantage of synthesized siRNA is that these molecules do not need to reach the nucleus to induce the therapeutic effect. As a drawback, stability must be improved in order to optimize the efficacy [54].

\section{Chemical modification of siRNA}

Gene silencing efficiency of siRNA also depends on its stability. Unmodified double-stranded RNA is much more stable as compared to single-stranded RNA. Nonetheless, the chemically modified nts utilized for synthesized siRNA have been introduced to further enhance its stability and thereby prolong its inhibition effects. The widely used class of modification involves modification of 2 ' position of the ribose ring. siRNA molecules with uniformly substituted 2' moieties in antisense and/or sense strands were not able to induce RNAi, whereas those with 2' modification at 3' overhangs or partial 2' modification in base-paired region improved their stability in serum without loss of RNAi activity [55]. Several studies have shown that some siRNAs with a phosphorothioate backbone are active in RNAi assay, but the activity is impaired with increasing degrees of 
modification [56]. An alternative backbone modification is the boranophosphate linkage, in which the non-bridging phosphodiester oxygen is replaced with an isoelectronic borane $\left(-\mathrm{BH}_{3}\right)$ moiety. Compared to phosphorothioate siRNAs, boranophosphate counterparts are more nuclease resistant and less toxic [57].

\section{3) Short hairpin RNA}

Short hairpin RNA (shRNA), also called expressed RNAi activator, is a plasmid coded RNA that needs to be transcribed in the nucleus to downregulate the expression of a desired gene. It can be transcribed through either RNA polymerase II or III. The first transcript generates a hairpin-like stem-loop structure and is then processed in the nucleus by a complex containing the RNase II enzyme Drosha. The individual pre-shRNAs generated are finally transported to the cytoplasm by exportin 5 . Once in the cytoplasm, the complex Dicer processes the loop of the hairpin to form a double-stranded siRNA. Since shRNA is constantly synthesized in the target cells, more durable gene silencing is achieved in comparison to other forms of RNAi. shRNAs represent an important tool in the assessment of gene function in mammals and are largely used as a research tool [58].

\section{Mechanisms of gene silencing of interfering RNAs}

RNAi leads to post-translational silencing of gene expression by multiple mechanisms, which include cleavage of target RNA, inhibition of translation, and sequestration into specific cytoplasmic compartments (Figure 11) [59]. The final effector of RNAi, from either the miRNAs or the siRNA or the shRNA pathway, is the ribonucleoproteins complex RISC, the catalytic component of which includes various members of the Argonaute (Ago) family of proteins. These proteins contain a PAZ domain, which binds miRNA/siRNA, and a PIWI domain, similar to that of RNases $\mathrm{H}$, which is the effector of target RNA cleavage in correspondence of a specific nucleotide, corresponding to nucleotide at position 10 of the guide filament. This endonucleolytic activity (also known as Slicer activity, which is apparently exerted by Ago2 but not by other members of the Argonaute family within RISC) requires perfect pairing between the guide filament in RISC and the target RNA, a condition that is usually sought when siRNAs are administered exogenously to the cell. In this condition, RISC functions as an enzyme, progressively destroying one molecule of substrate after the other. In the case of most endogenously produced miRNAs, in contrast, pairing usually occurs with the 3' UTR of the target mRNA and is not perfect, only requiring $7 \mathrm{nt}$ at the 5' end of the guide filament (from nucleotide in position 2 to nucleotide in position 8); these 7 nucleotidesnform the so-called seed sequence. In this case, silencing of gene expression is mainly due to the inhibition of translation of the target mRNA. Finally, a third mechanism of gene silencing is due to the ability of the RISC-associated Argonaute proteins to sequester the target mRNAs within specific cytoplasmic compartments, called P bodies, in which RNA degradation is believed to occur [59] [60].

RNAi application to viral infection

Because of the large therapeutic potential offered by RNAi against the pathogenic 


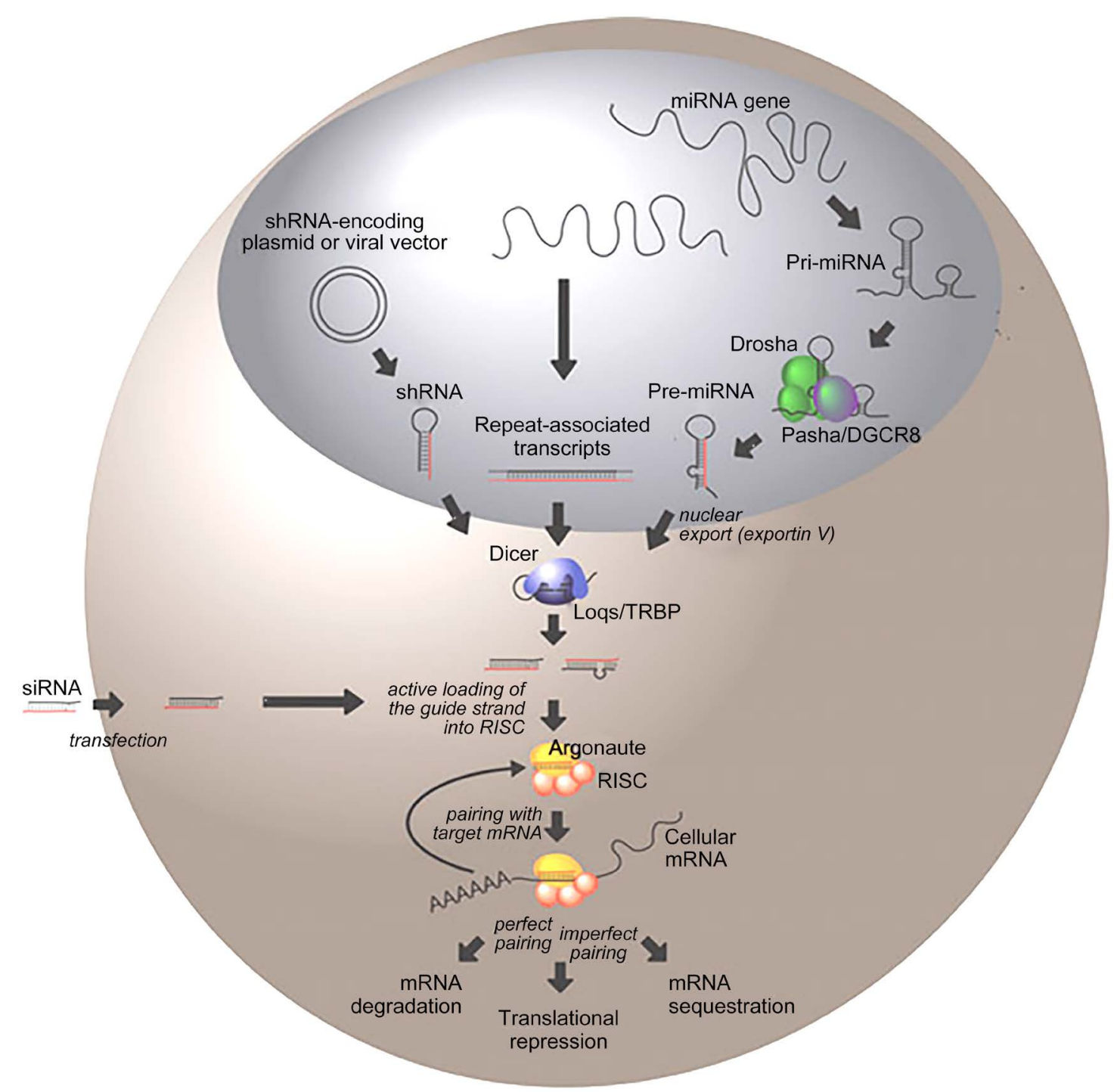

Figure 11. An overview of biogenesis and intracellular processing of RNAi inducers.

viruses, many of them are being considered for medical use in the near future (Figure 12). It works against RNA viruses with negative- or positive-strand genome polarity, as well as against DNA viruses [6]. The RNAi, as a therapeutic tool, can be targeted against the various phases of the viral life cycle of DNA and RNA viruses including replication, transcription, assembly of new virions, and budding out of the target cells (Figure 13) [61].

\section{1) RNAi prevents viral infection}

The ability of synthetic siRNAs to inhibit viral production was determined in cultured cells by introducing siRNAs into the cells before viral infection and then assaying virus titers in the culture supernatants at different times after infection [62]. Influenza virus causes one of the most prevalent infections in humans. Introducing siRNAs and shRNA expression constructs into cultured cells and chicken embryos before virus infection was able to inhibit influenza virus production, especially those encoding NP, PA, and PB1. In addition, RNAi 


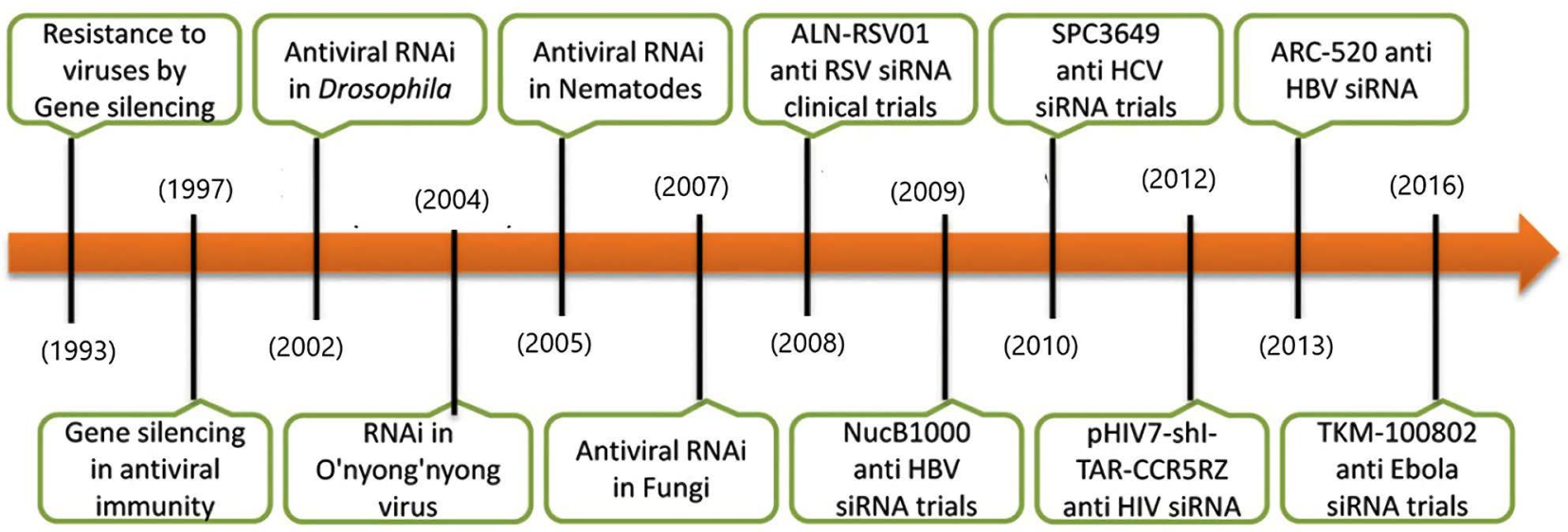

Figure 12. Timeline summarizing different stages in the course of development of RNA interference (RNAi)-based therapeutics against viruses.

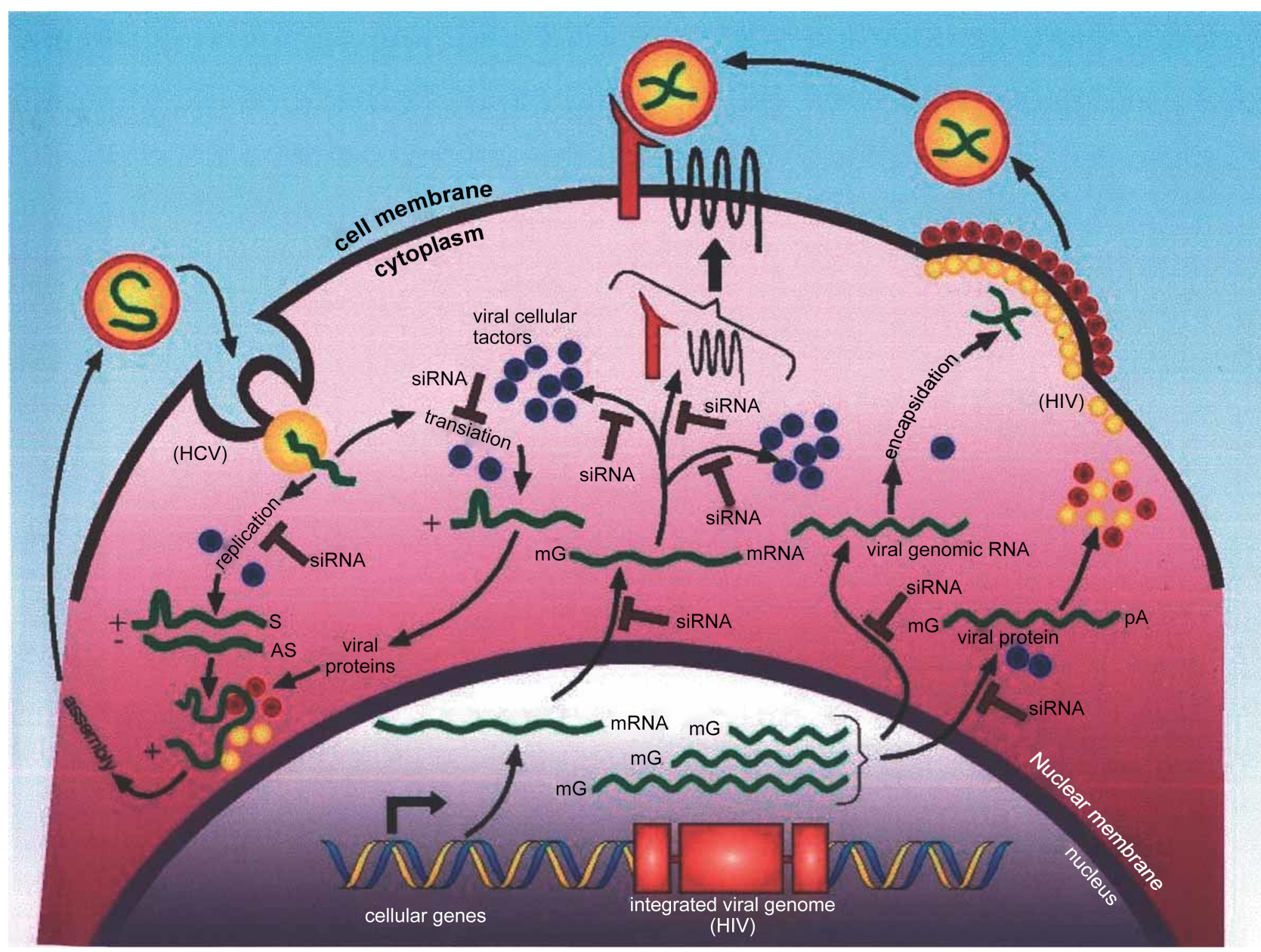

Figure 13. Potential sites that RNAi could be affecting viral infection. This is a simplified pictorial description of the host cells attacked by two types of RNA viruses. The left side of the illustration describes possible targets against an enveloped + strand virus, in this case $\mathrm{HCV}$; the right side shows an integrating RNA virus, in this case HIV.

inhibitory effects also occurred in cells that had been infected with virus prior to siRNA and shRNA introduction [63]. 
Poliovirus, a RNA virus, is able to invade the nervous system and cause paralysis. Gitlin et al. revealed that RNAi effectively prevented viral infection in mammalian cells by using siRNAs against the poliovirus genome [62]. Hepatitis $\mathrm{C}$ virus (HCV) infection is a major cause of chronic liver disease, which can lead to the development of liver cirrhosis and hepatocellular carcinoma. NS3 and NS5B siRNAs could specifically inhibit HCV RNA replication and protein expression in Huh-7 cells [64]. AcNPV (A. californica nucleopolyhedrovirus) is a member of baculoviruses family that naturally infects many different insect species. The introduction of dsRNA containing a sequence from iel or ie1-siRNAs into Sf21 cells and living insects could protect them against baculovirus infection. The inhibitory effects of siRNAs could be stable inside cells for over a week [65].

\section{2) RNAi inhibits the expression of viral antigens}

Many viral proteins don't involve in viral RNA or protein synthesis, but take part in pre- or post-transcriptional aspects of the viral life cycle. A number of cellular membrane molecules may act as receptors for viruses. RNAi has widely been used in the inhibition of the expression of viral surface antigens in the research of viral diseases. CCR5, a human chemokine receptor protein, is a necessary coreceptor for infection by most strains of HIV-1. When siRNAs against CCR5 were introduced into human peripheral blood $\mathrm{T}$ lymphocytes, the expression of potent CCR5-siRNA would result in up to 10-fold inhibition of CCR5 synthesis on the cell surface over a period of 2 weeks [66].

Paramyxoviruses initiate infection by attaching to cell surface receptors and fusing viral and cell membranes. Three viral attachment proteins, glycoprotein $(\mathrm{G})$ receptors, hemagglutinin-neuraminidase $(\mathrm{HN})$ and fusion $(\mathrm{F})$ proteins direct membrane fusion (formation of syncytia). The siRNA knockdown of F resulted in complete loss of syncytium without G or SH synthesis [67]. SARS-CoV (the SARS-associated coronavirus) has been classified as a novel member of the coronavirus family with a spike protein, which plays an important role in viral entry and pathogenesis. DNA vector-driven siRNA and shRNA plasmids against the spike protein of SARS-CoV could electively and specifically silence gene expression of the Spike protein in SARS-infected 293T cells [68].

\section{3) RNAi suppresses the transcription of viral genome}

Viruses need to transcribe its genome after entering the host cells. In addition to using cellular factors, viruses can generate their transcriptional activators such as E6 and E7 proteins of human papillomaviruses (HPVs). E6 siRNAs and shRNAs were transfected into HPV16-related cervical cancer cells. Experiments demonstrated that E6 siRNAs and shRNAs were potent in the suppression of viral oncogene expression. For RNA viruses, especially in retroviruses, gag, env and pol are essential for genome transcription. Avian Sarcoma Leucosis Virus (ASLV) is a positive-RNA virus. siRNAs matching two sequences in the gag gene of ASLV were introduced into cultured chicken DF-1 cells. After DF-1 cells were co-transfected by ASLV and siRNAs, the production of the RCAS virus in culture supernatants was dramatically reduced (90\%) 2 day after treatment [69]. 
Moreover, the inhibition of transcription by anti-gag siRNAs and anti-env siRNAs against HIV-1 virus genome was also observed in CD4-positive cells [70].

\section{4) RNAi blocks viral replication}

Once a virus has entered a cell, it needs to replicate its genome. It has been shown that RNAi is induced by virus replication in animals. Activation of RNA silencing is thought to be involved in the inhibition of viral replication. West nile virus (WNV) is an enveloped arbovirus with a single-stranded, 11-kb positivepolarity RNA genome. siRNAs specific for WNV capsid or NS5 ORF were constructed in pHH21 and then transfected into 293T cells. Subsequently, the treated cells were infected with WNV. It was showed that WNV protein expression, genomic RNA synthesis, and infectious virus production were all dramatically reduced by siRNAs targeting these two distinct viral sequences [71]. The HBV genome is a double-stranded DNA molecule and generates four viral RNAs that encode the core protein/HBeAg and polymerase-reverse transcriptase, $\mathrm{HBsAg}$, and $\mathrm{X}$ protein, respectively. Human hepatoma cells were co-transfected with HBV and siRNAs against HBV pre-genome RNA. The results also indicated that siRNA-mediated gene silencing could inhibit HBV replication through suppression of viral RNA [72]. shRNAs targeting HBV sequences also effectively inhibited viral replication and the production of core antigen in hepatocytes [73].

\section{5) RNAi silences viral accessory genes}

There are many accessory genes in viruses. These genes take part in the viral pathogenesis such as latency and persistence and regulate the expression of other genes. Silencing these genes should be good therapeutic strategies for the treatment of viral diseases. Epstein-Barr virus (EBV) is a prototype gamma herpesvirus with a dsDNA genome. Latent membrane protein-1 (LMP-1), encoded by $\mathrm{EBV}$, is thought to be the only oncoprotein playing an essential role in cell transformation as well as nasopharyngeal carcinoma (NPC) metastasis. Li et al. showed that the stable suppression of LMP-1 by shRNA plasmid significantly altered EBV-positive NPC cell (C666) motility, substratum adhesion, and transmembrane invasion ability [74]. Application of RNAi to the study of accessory genes provides a chance to learn more about molecular mechanisms underlying viral infection so that people could develop more effective drugs to treat viral diseases.

\section{6) RNAi hinders the assembly of viral particles}

Assembly of viral particles varies with different virus families. The formation of the virus caspid has been well studied. Many caspid proteins are involved in the assembly of virus particles including VP4 and matrix proteins. Rotavirus causes severe diarrhea in infants and children worldwide. To combat this virus, Dector et al., utilized siRNA directed to the VP4, a viral structural protein that is essential for the attachment of the infecting virus to the cell surface. They showed a significant reduction in the number of viral particles produced in MA104, an infected monkey kidney cell line [75]. Vesicular stomatitis virus (VSV) is a member of non-segmented negative-stranded RNA viruses. VSV matrix gene (M) mRNA was shown to produce three proteins: M1, M2 and M3. M 
protein(s) can inhibit host gene expression and cause apoptosis of the host cell. In an attempt to determine which product of the $\mathrm{M}$ gene mRNA is involved in apoptosis and cell-rounding, siRNAs targeting to the region of target mRNA that is unique to M1 and upstream of M2 and M3 were transfected into HEp-2 cells. Results showed that these siRNAs abrogated the expression of all three proteins, and the cell detachment was concomitantly inhibited [76].

\section{7) RNAi displays roles in virus-host interactions}

Viruses can control both viral and cellular gene expression while host cells can also protect themselves against virus infection through immune response. The suppression of these genes by siRNAs can be also used to address the role of such genes in host-virus interaction. HCV belongs to the family Flaviviridae with a positive RNA genome. To determine whether HCV expression is interfered with RNAi, siRNAs against cellular (LaminA/C) and viral (HCV) RNAs were introduced into Huh-7.5 cells containing replicating HCV. Both cellular and viral RNAs were effectively silenced [77]. Bitko and his colleagues recently applied siRNAs-knockdown technology to determine the role of profilin in the RSV life cycle. It was showed that profilin stimulated RSV transcription in vitro, but was not absolutely necessary for virus replication in the previous studies. The knockdown of profilin showed that it had a minor effect on viral transcription but strongly inhibited the formation of actin stress fibers [67]. Nodaviral infection can trigger an RNA silencing-based antiviral response (RSAR) in Drosophila RSAR, which is a rapid virus clearance in the absence of expression of a virus-encoded suppressor. Li et al. showed that Drosophila RSAR was mediated by the RNA interference (RNAi) pathway, as the viral suppressor of RSAR inhibited experimental RNAi initiated by exogenous double-stranded RNA. Specific RNA silencing was induced by IFN. Antagonist proteins encoded by viruses are suppressors of the Drosophila S2 cells in response to viral RNA replication. Furthermore, this mosquito antiviral immunity is RISC dependent and sensitive to suppression evoked by the B2 protein encoded with either FHV or nodamura virus (NoV) [78]. The study of virus-host interactions can promote the understanding of RNAi machinery as well as the application of RNAi in the viral diseases, which will extremely draw more researchers to dedicate to it.

\subsection{Classes of Antiviral Nucleic Acid-Based Therapeutics Targeting Viral Proteins}

\subsubsection{Antibody Genes}

Antibody immunotherapy is revolutionizing modern medicine. Monoclonal antibodies are successfully used in the clinic. Antibodies are a crucial part of the body's specific defense against infectious diseases and have considerable potential as therapeutic and prophylactic agents in humans and animals. The field has advanced dramatically over the past 40 years, driven in part by major advances in isolation and manufacturing technologies that have brought these important biologics to the forefront of modern medicine. However, the global uptake of monoclonal antibody biologics is impeded by biophysical and biochemical lia- 
bilities, production limitations, the need for cold-chain storage and transport, as well as high costs of manufacturing and distribution. Some of these hurdles may be overcome through transient in vivo gene delivery platforms, such as non-viral synthetic plasmid DNA and messenger RNA vectors that are engineered to encode optimized monoclonal antibody genes (Table 2). An alternative approach would be to leave the production of therapeutic antibodies to the body itself. These approaches turn the body into a biological factory for antibody production, eliminating many of the steps involved in bioprocesses and providing several other significant advantages, and differ from traditional gene therapy approaches. In general, the antibody heavy- and light-chain complementary DNA (cDNA) are examined and then optimized or designed for encoding and expression specifically for the type of vector chosen for in vivo delivery (Figure 14) [79]. The development of recombinant single-chain antibodies allows a genetic application strategy for prevention of infectious diseases. Genetic resistance to viruses would be a desirable alternative to vaccination [79].

Close to 4 billion people are estimated to be at risk for dengue virus infection worldwide, mostly in developing countries and in resource-poor settings. Flingai et al. demonstrated the first generation of DNA-encoded monoclonal antibody

Table 2. Comparison of different in vivo antibody gene delivery platforms [79].

\begin{tabular}{|c|c|c|c|}
\hline Characteristics & Synthetic DNA & mRNA & Viral vector \\
\hline Starting material & Plasmid DNA & Plasmid DNA & Plasmid DNA \\
\hline Injected material & Plasmid DNA/by EP & mRNA in LNP & AAV, Ad vector \\
\hline In vivo product & mAb, BsMAb & mAb, BsMAb & $\mathrm{mAb}, \mathrm{BsMAb}$ \\
\hline Transient & Yes & Yes & $\begin{array}{c}\text { Yes; however, rare cases } \\
\text { may integrate (AAV) }\end{array}$ \\
\hline Cell compartment & Nucleus & Cytoplasm & Nucleus \\
\hline Integration & $\begin{array}{l}\text { None observed in } \\
\text { humans }\end{array}$ & Low probability data early & Possible \\
\hline Anti-vector immunity & No & No & Yes, serotype specific \\
\hline $\begin{array}{c}\text { Duration of a single } \\
\text { administration }\end{array}$ & Weeks/months & Days/weeks & Months/years \\
\hline Delivery route & ID, IM & IV, IM/ID & IM, IN, IV, IC, IO, IT \\
\hline $\begin{array}{l}\text { Tissue specificity/ } \\
\text { tropism }\end{array}$ & $\begin{array}{c}\text { Local site of } \\
\text { administration }\end{array}$ & Non-specific & Serotype dependent \\
\hline Vector take & High in animals & High in preclinical & Variable \\
\hline Human safety & Very safe & $\begin{array}{l}\text { Ongoing trials, } \\
\text { SAEs reported }\end{array}$ & $\begin{array}{l}\text { Safe but potential for } \\
\text { integration }(\mathrm{AAV})\end{array}$ \\
\hline Ease of manufacturing & Yes & Likely yes with caveats & Moderate \\
\hline Cold-chain free & Yes & $\begin{array}{l}\text { Possible (with LNP) } \\
\text { No (without LNP) }\end{array}$ & No \\
\hline
\end{tabular}




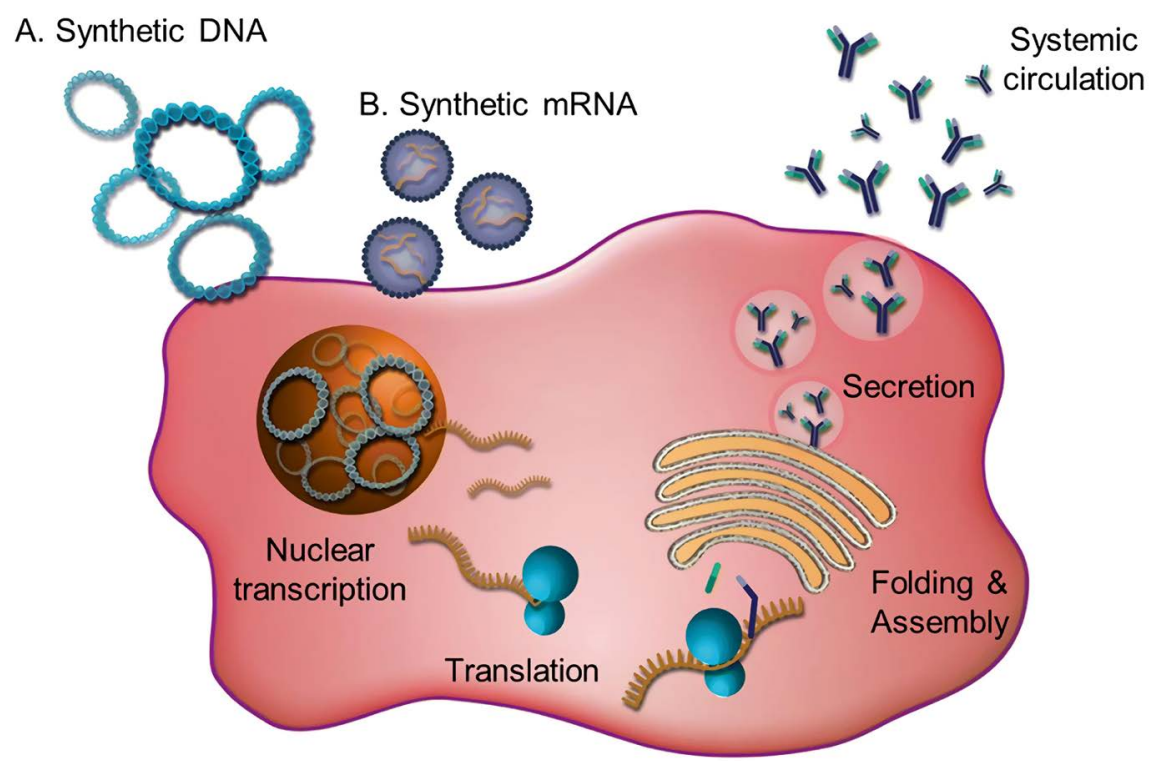

Figure 14. Nucleic acid antibody gene delivery using synthetic DNA or mRNA administration into the cell.

engineering and delivery of anti-dengue virus antibodies. The anti-dengue virus DNA-encoded monoclonal antibody achieved peak expression levels of around 1 $\mu \mathrm{g} / \mathrm{mL}$ for at least 19 weeks in mice and demonstrated neutralization of dengue virus serotypes 1 - 3. The anti-dengue virus LALA-DNA encoded monoclonal antibody demonstrated protection against primary dengue infection [80]. Advancing monoclonal antibody delivery could have an important impact on lowering overall influenza disease burden during seasonal influenza epidemics and against potential pandemic viruses. Yamazaki et al. were one of the first to show in vivo expression of a pDNA-monoclonal antibody anti-influenza A virus hemagglutinin (HA) mouse IgG1 antibody. They demonstrated initial expression of approximately $1 \mu \mathrm{g} / \mathrm{mL}$ anti-HA antibody in mice. The pDNA-monoclonal antibody expressed anti-HA antibody was detectable in lung bronchioalveolar lavage and protected mice against lethal A/H1N1/Puerto Rico/8 virus challenge [81].

The 2013-2016 Ebolavirus disease (EVD) epidemic was the largest to date, with over 28,000 confirmed cases and over 11,000 deaths. Antibodies against the Zaire ebolavirus GP are demonstrating promising therapeutic protection against EVD. The three-monoclonal antibody ZMapp cocktail was the first antibody combination to demonstrate promise in an EVD outbreak setting. Andrews et al. encoded the ZMapp cocktail antibodies into their pDNA-mAb platform, showing delivery of each individual mouse IgG2a antibody to a maximum of 10 $\mu \mathrm{g} / \mathrm{mL}$ and $30 \mu \mathrm{g} / \mathrm{mL}$ for combined delivery and 13 weeks of in vivo expression. The pDNA-ZMapp was delivered to mice, followed by challenge 28 days later with mouse-adapted Ebolavirus, demonstrating protection against lethal infection [82].

There are approximately 37 million people living with HIV, with the envelope 
GP (Env) being the primary target for immune responses. Due to the high diversity of Env proteins, vaccine development and therapy have been challenging. Wise et al. engineered a panel of 16 broadly neutralizing HIV-1 antibodies as DNA-encoded monoclonal antibodies and delivered them in mice and non-human primates.

\subsubsection{Decoys}

The term "decoy" refers to small DNA or RNA molecules (30 - $100 \mathrm{nt}$ in length) containing the same binding site of a DNA or RNA binding protein. They are designed according to the nucleic acid consensus sequence recognized by a particular protein, therefore they possess a structure which mimics or is identical to the real ligand, thus acting as ligand antagonists. As a consequence, these molecules are able to compete, once present in high concentration inside the cells, with the endogenous nucleic acids for binding to this protein, thus diverting it from its natural target. Decoy oligonucleotides usually mimic the consensus binding site of a transcription factor. Gene expression controlled by this transcription factor is effectively prevented, thereby effectively silencing gene expression and preventing the protein from being produced (Figure 15) [50]. Therefore, being less specific in comparison with the small interfering RNA or antisense oligonucleotide method, the decoy oligonucleotide technique can be considered as a gene silencing approach. Nevertheless, decoys have been shown to be highly specific for their target transcription factor [83].

An applicative example of a decoy is found in gene therapy for infectious disorders. Replication of HIV-1 is highly dependent on binding of two of its proteins, the Tat trans activator and the regulatory Rev protein, to specific cis-acting

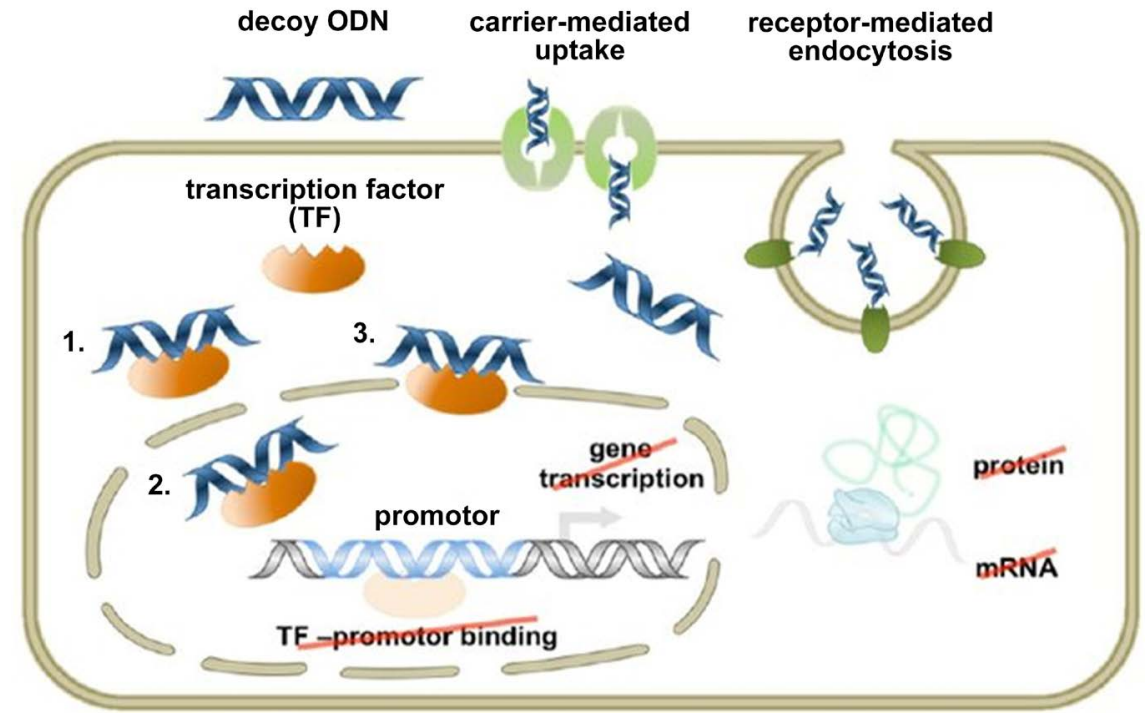

Figure 15. Mechanism of action of double-stranded decoy oligodeoxynucleotide (ODN). Scheme depicting the mechanism of action of decoy ODN-mediated neutralization of the targeted transcription factor (TF). 1 refers to cytoplasmic TF sequestration, 2 to nuclear TF sequestration, and 3 to removal of promotor-bound TF through titration with highaffinity decoy ODNs. 
sequences on viral RNA, the TAR (trans-acting response) and RRE (Rev-responsive element) respectively. In the absence of Tat, transcription of proviral DNA does not occur, while the absence of Rev blocks export of the viral unspliced mRNAs into the cytoplasm. The intracellular expression of high amounts of short RNA sequences corresponding to either TAR (TAR decoy) or RRE (RRE decoy) diverts the respective binding proteins from their natural targets and thus inhibits viral replication [84] [85]. One of these decoy sequences (multimeric TAR) is present in one of the lentiviral vectors that have recently entered a clinical trial [86].

The success of the decoy-based therapeutic approaches is usually limited by the high concentration at which these molecules must be continuously present in the cells to act in a competitive manner. Such a concentration is usually difficult to obtain by extracellular administration. At least for the RNA decoys, this problem can be overcome by the intracellular expression of these molecules upon delivery of the respective genes. In addition, the DNA decoys are usually less efficient than the natural promoter DNA in binding a transcription factor, since, in the latter case, factor binding is stabilized by chromatin structure and interaction with the other proteins involved in transcription [87].

\subsection{Classes of Antiviral Nucleic Acid-Based Therapeutics Targeting Viral Nucleic Acids or Viral Proteins \\ Aptamers}

The term aptamer was coined in 1990 from the Latin "aptus" meaning "fitting" and the Greek "meros" meaning "particle". Nucleic acid aptamers are 30 to 100 nt long single-stranded oligonucleotides (RNA or DNA) with low molecular weight (ranging 5 - $40 \mathrm{kDa}$ ), which capable of adopting complex tertiary structures that allow noncovalent interactions with other molecules [88]. Because aptamers closely interact with their targets, their structural features are essential for highly specific binding. They interact with high specificity and affinity with their target molecule and the tight binding often affects the activity of the target molecule (Figure 16) [89]. These molecules are well suited for therapeutic applications because of their remarkably high affinity and specificity towards their targets, the lack of toxicity and immunogenicity [90].

\section{In vitro SELEX method}

The strategy to obtain specific aptamers is called SELEX for its acronym in English Systematic Evolution of Ligands by EXponential enrichment. Two independent groups in the United States simultaneously published this method, one at the University of Colorado, and one at Harvard University. Briefly, the SELEX strategy starts with a pool of RNA or DNA of $10^{14}$ to $10^{15}$ random sequences that interact with a target protein (Figure 17) [91]. This large combinatorial oligonucleic acid library (DNA or RNA) consisting of an inner random region flanked by two constant regions. The oligonucleotides that bind the target are retrieved, while the others are discarded. The selected oligonucleotides are PCR-amplified (or RT-PCR amplified in the case of RNA aptamers) to perform additional 


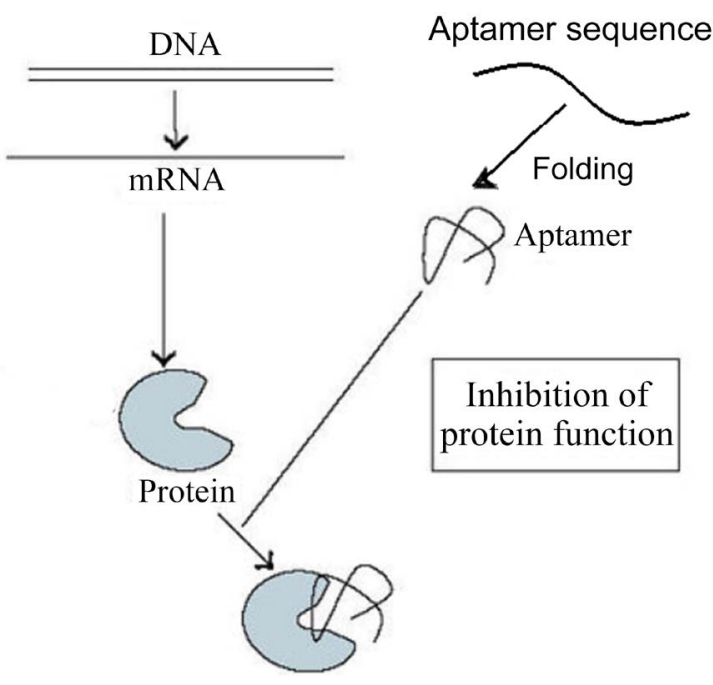

Figure 16. Schematic representation of the mode of action of aptamers. Antisense, ribozymes, siRNAs, miRNAs recognise the target nucleic acid by complementary base pairing and, by activating an intracellular molecular machinery, impair the expression of the corresponding protein. Aptamers act by directly binding the target without interfering with its expression.

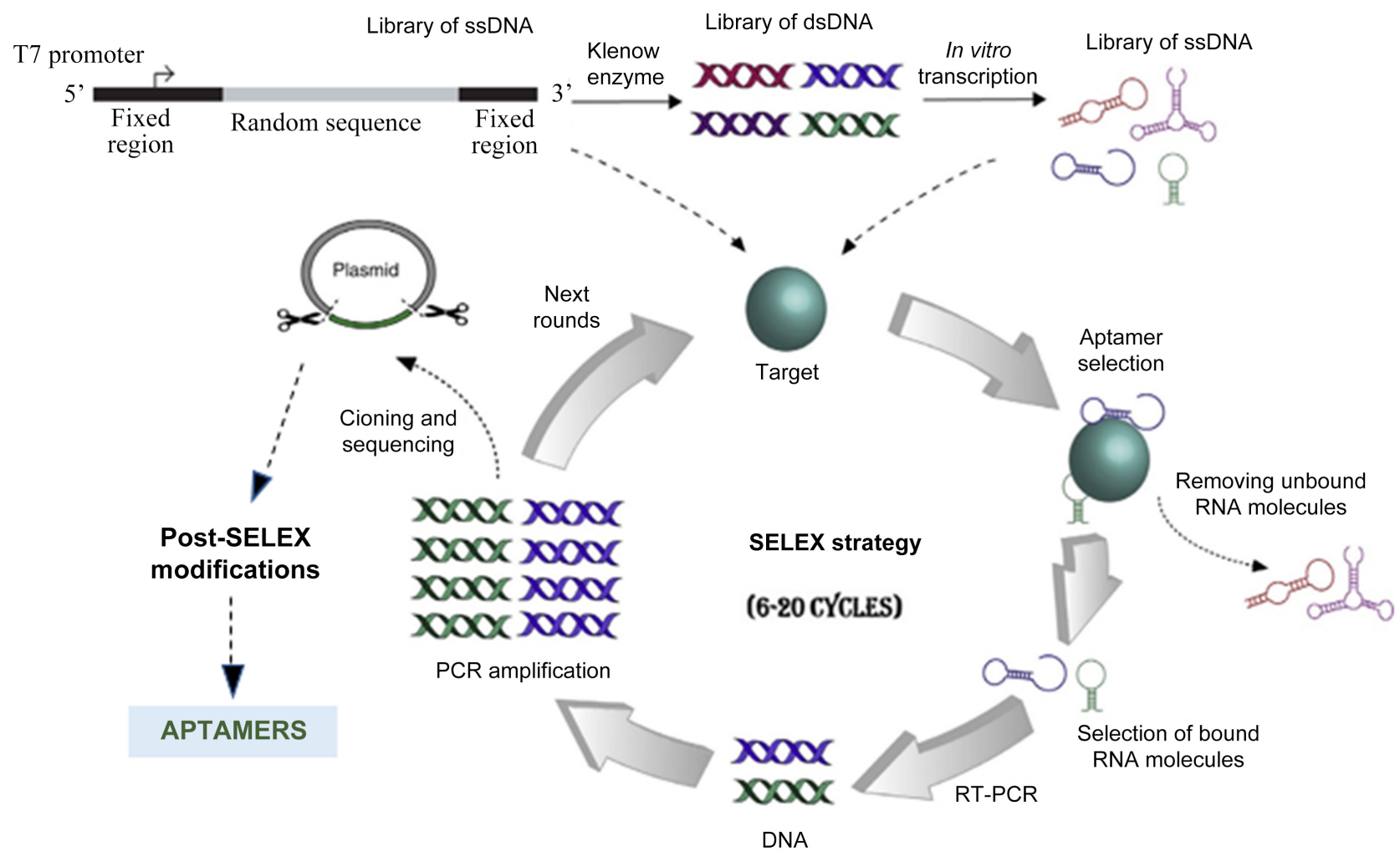

Figure 17. Graphical representation of the SELEX strategy. The initial library of ssDNA may be used immediately for interaction with the target, while the generation of ssRNA library requires additional steps for synthesis of complementary strand by Klenow enzyme and in vitro transcription. Then, selected aptamers are PCR amplified to start a new round of SELEX.

rounds of selection until more than $90 \%$ of aptamers interact with the target. After that, cloning and sequencing of aptamers is performed to identify a con- 
sensus motif between selected aptamers [88] [92]. This universal process must be standardized for the selection of each target-specific aptamer by varying the target concentration, the number of rounds, and the stringency of the binding conditions, among others. So far, this approach has allowed the selection of highaffinity DNA or RNA aptamers for a variety of targets including small molecules such as amino acids and antibiotics, proteins and even complex targets, i.e. whole cells and viruses [79].

\section{Aptamers in the treatment of viral infections}

Aptamers have a very broad application range, and are used as diagnostic agents, for target validation and clinical application (Table 3). Additionally, due to their high similarity in function and affinity towards the targets, aptamers are used as substitutes for antibodies and applied in several systems as capture agents, to monitor protein-nucleic acids and protein-protein interactions [93]. Aptamers might be used not only to treat the infection, but also to prevent it-viral infection can be inhibited in almost any step of the disease. Many studies confirmed that the most effective therapeutic strategy is to block the penetration of viruses into the cells and/or inhibition of enzymes involved in their replication (Figure 18) [94]. They are suitable subjects of structural modifications as in vivo biostability improvement and conjugation with other therapeutic molecules, such as s mall interfering RNA (siRNA) and ribozymes [95] [96].

\section{1) Blocking of viral fusion with the target cell}

One of the most obvious and frequently studied therapeutic strategies is an inhibition of the viral fusion with the target cell. Viruses penetrate into the cells, using specific surface proteins, which serve as ligands for superficial human molecules. As commonly known, many viruses show a tropism for specific cell types,

Table 3. A summary of several aptamers developed for the treatment of viral infections by SELEX method [112].

\begin{tabular}{|c|c|c|c|}
\hline Organism & Type of aptamer & Target & Aptamer therapeutic effect \\
\hline $\mathrm{HBV}$ & DNA & Core protein & $\begin{array}{l}\text {-Prevent the assembly of the nucleocapsid } \\
\text {-function by suppressing HBV replication }\end{array}$ \\
\hline $\mathrm{HCV}$ & DNA & Envelope Protein & -Inhibition of virus binding to host cells \\
\hline Influenza A virus & DNA & Hemagglutinin protein & $\begin{array}{l}\text {-Blocking the binding of virus to target cell receptors } \\
\text {-prevention of the virus invasion into the host cells }\end{array}$ \\
\hline Ebola Virus & RNA & VP35 & -Disrupt the eVP35-NP interaction \\
\hline HIV-1 & RNA & gag protein & -Inhibit HIV-1 replication \\
\hline HSV-1 & RNA & gD protein & -Blocking the gD functions \\
\hline Vaccinia virus & DNA & Hemagglutinin protein & $\begin{array}{l}\text {-Recognize proteins } \\
\text { expressed on the surface of VV-infected cells }\end{array}$ \\
\hline Influenza B Virus & RNA & Hemagglutinin protein & -Inhibited HA-mediated membrane fusion \\
\hline SCV & RNA & $\mathrm{nsP} 10$ & -Inhibit double-stranded DNA unwinding activity of the helicase \\
\hline Rabies virus & DNA & $\begin{array}{l}\text { Blocking the interaction between rabies } \\
\text { virus and permissive host cell receptors }\end{array}$ & -Reduced viral replication in an in vitro infection model \\
\hline
\end{tabular}




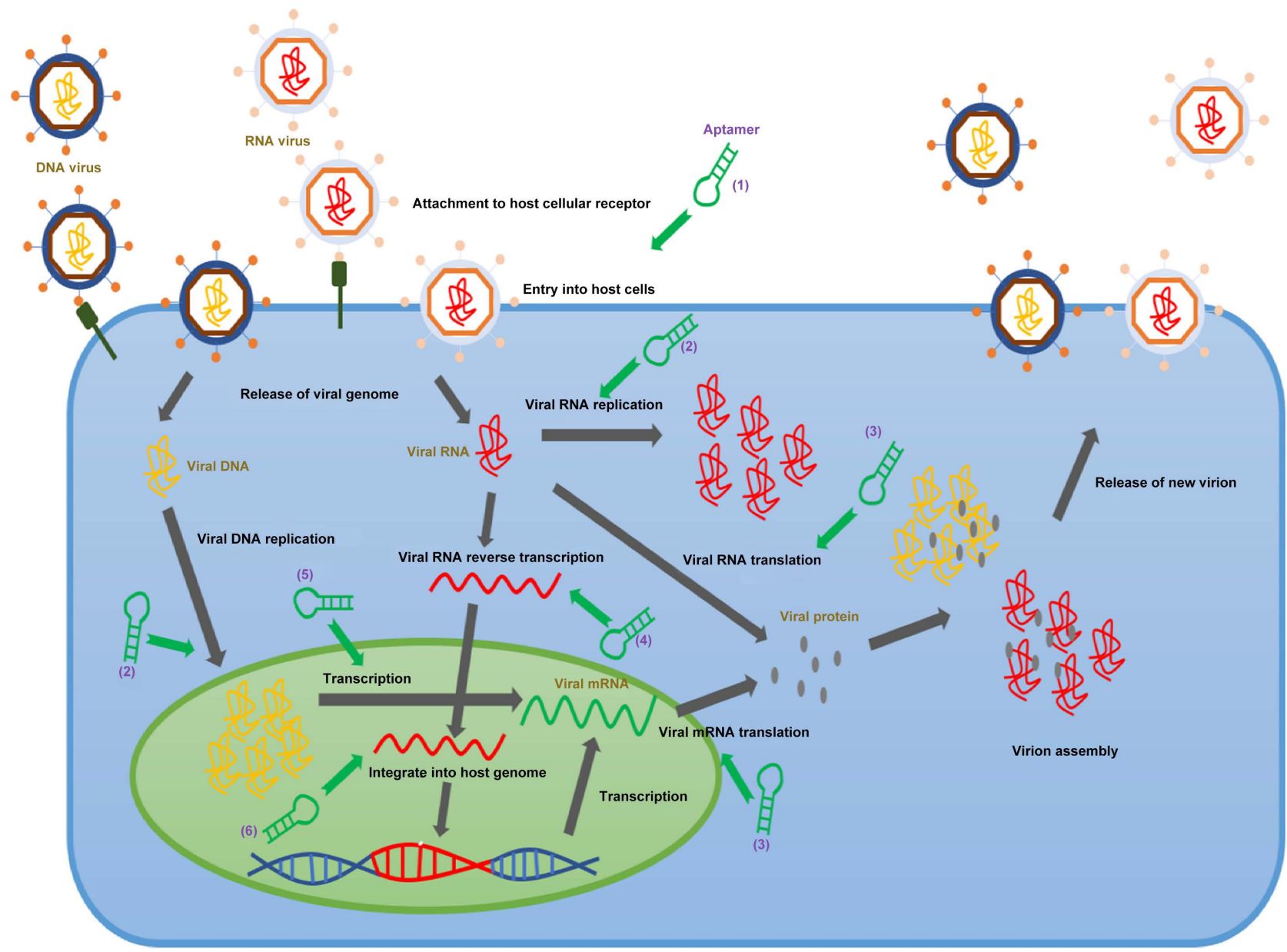

Figure 18. The strategies of antiviral therapy with use of aptamers. The life cycle of a virus consists of attachment, entry, replication, assembly, and release. Aptamers can target factors involved in each step. (1) Aptamers can block viral entry into host cells by targeting host cell receptors or virus structural proteins. (2) Viral genome replication can be suppressed by targeting proteins such as viral polymerases and helicases. (3) Proteases, which are involved in the production of viral proteins, can be inhibited with aptamers thereby inhibiting viral replication. (4) The reverse transcription process can be prevented by targeting the reverse transcriptase involved in the RT of the viral RNA of retroviruses such as HIV. (5) Viral mRNA generation can be prevented by targeting factors involved in the transcription of the viral genome. (6) By targeting viral integrases, proviruses of viruses such as HIV can be prevented from being integrated into the genome of the host cell.

i.e., HCV, HBV and HIV-1. HIV-1 glycoprotein gp120, the ligand of T helper cell receptor, CD4, was inhibited by Dey et al. who used RNA aptamer B40, and its shorter variant, B40t77. Moreover, they blocked gp120 binding by its $\mathrm{T}$ cell co-receptor, CCR5 (C-C Chemokine Receptor type 5). They observed decrease in concentration of p24 HIV-1 antigen in supernatants from virus-infected cultures of human PBMCs (Peripheral Blood Mononuclear Cell), as measured by ELISA assay and number of virus copies in qPCR (quantitative real-time PCR) assay [97]. In HCV infection, E2 glycoprotein was a potential target for aptamer approach. E2 is a co-receptor of human CD81, presented on hepatocytes and B lymphocytes. Chen et al. constructed DNA aptamer, assigned as ZE2, competitively blocking E2 in majority of HCV serotypes. The decrease of both: viral RNA levels in the qRT-PCR (reverse transcription-qPCR) analysis and E2 pro- 
tein concentrations in the Western blot assay were demonstrated [98]. Another application relates to conserved-HA regions of influenza virus. Jeon et al. selected A22 DNA aptamer that bound HA specific site, responsible for ligation of human cell receptor. The aptamer-dependent prevention the viral fusion to the target cells was confirmed by in vitro cultures in established Madin-Darby Canine Kidney (MDCK) cell line, by measuring the viability of cells after exposure to influenza virus [99].

Wang et al. adopted the same strategy into human cytomegalovirus (HCMV) infection. They obtained two RNA aptamers (L13 and L19) directed against superficial viral ligand glycoproteins $\mathrm{B}$ and $\mathrm{H}$. Aptamers reduced cytomegalovirus infectivity, as it was proven in Human Foreskin Fibroblast (HFF) cell line culture. They were preincubated with aptamers and then exposed to HCMV viral particles [100]. Aptamer against HSV-1 were designed by Gopinath et al. They inhibited viral glycoprotein D, ligand of nectin-1, an actual HSV entry mediator receptor (HVEM). Initially, selected aptamer was too long (113 nt), so it was reduced to $44 \mathrm{nt}$ and modified with 2'-fluoropyrimidines to improve its biostability. Reduced infectious potential of HSV-1 was observed in aptamer dose-dependent manner during plaque formation test in the African green monkey kidney (VERO) cell culture [101].

\section{2) Inhibition of proteins and enzymes of viral replication cycle}

Another strategy, with the effectiveness comparable to blocking the viral fusion with the cells, is an inhibition of enzymes or other proteins involved in viral replication, transcription and translation.

\section{a) Blocking of viral enzymes with polymerase activity}

HCV viral protein NS5B (Nonstructural protein 5B), RNA-dependent RNA polymerase, is the promising target for aptamer treatment, because of its significance for the virus replication (HCV is a single stranded RNA virus). Biroccio et al. selected RNA aptamer B.2., characterized by stem-loop structure, with a specific sequence UAUGGACCAGUGGC recognizing a key element-a GTP binding site of NS5B-responsible for its function. Inhibition of polymerase activity was positively correlated with aptamer concentration, as in vitro analysis of the polymerase activity has shown [102]. Feng et al. investigated anti-HBV RNA aptamer, designated as S9. S9 interacted with viral polymerase with high affinity and competed a binding site of viral genetic material. It inhibited HBV replication (reduction of replicative intermediates by about $80 \%-85 \%$ ) in human infected cell line (HepG2.2.15), as it was assessed by Southern blot analysis after the cell line transfection with a plasmid vector encoding S9 RNA aptamer [103].

\section{b) Blocking the activity of other enzymes involved in viral replication}

Except polymerases, there are other enzymes, which are indirectly involved in virus replication. The best known is NS3 protein (Nonstructural protein 3) consisted of two domains (C- and N-terminal one) with helicase and protease activity, respectively. Both domains are essential for the replication of Flaviviridae family, including HCV. Under physiological conditions, the helicase domain has 
an affinity to the poly $(\mathrm{U})$ sequence located in the $3^{\prime}$-untranslated region of the viral genome (3'-UTR) [104]. Umehara et al. generated a bivalent aptamer with sequences connected by a poly(U) linker. In series of experiments they determined the optimum length of the linker, i.e., 41 and 50 nt. As a result, NEO35-s41 and G925-S50 aptamers with the highest simultaneous reduction of NS3 both helicase and protease activity have been obtained [105]. One of a few discovered proteins of life-threatening coronavirus SARS is nsP10 (Nonstructural Protein 10) enzyme with NTPase/helicase activity. Jang et al. targeted nsP10, applying specific RNA aptamer, ES15, which secondary structure contained stemloop structure with AG repeats. During in vitro analysis it inhibited viral enzyme activity in a dose-dependent manner, up to $85 \%$ of baseline value, what was confirmed by fluorescence resonance energy transfer (FRET) test [106].

3) Inhibition of nucleic acid sequences essential for virus replication cycle

The opportunity to select aptamers targeting any molecule, not only protein, makes it possible to use them against viral nucleic acids. Certain regions of their genome interact with proteins responsible for transcription initiation, translation and replication or viral assembly. The generation of aptamers with selective affinity to these regions seems to be promising therapeutic approach.

An Internal Ribosome Entry Site (IRES) of HCV mRNA, involved in viral translation, is a potential attractive therapeutic target, due to its conservative sequence. IRES is composed of four domains, I-IV, located in the 5 -untranslated region (5'-UTR). It is responsible for the initiation of viral replication and mRNA cap-independent translation. IRES binds the small ribosomal subunit (40S) in the host cell, and eukaryotic Translation Initiation Factor 3 (eTIF3). Konno et al. applied RNA aptamer AP30, directed against domain I of IRES located at the 3' end of the viral genome antisense strand. AP30 inhibited HCV genetic material replication during in vitro analysis by about $50 \%$. Its consensus sequences 5 'UGGAUC-3' and 5'-GAGUAC-3', which were complementary to the SL-E1 and SL-D1 loops in the domain I were responsible for this effect. In this way they prevented attachment of viral RNA polymerase, NS5B, mentioned above [107].

Romero-Lopez et al. combined the activity of hammer head ribozyme (HH363) with properties typical for aptamers. The construct, assigned as HH363-24, bound IRES domain IIId and cleaved the HCV genome in 3' side. It led to simultaneous inhibition of both viral translation and replication. Mutational analysis showed that the inhibitory effect depended not only on typical anti-HCV RNA activity, but on enzymatic ribozyme cleavage activity as well [108]. Some other attempts were focused on aptamers binding to HIV-1 Long Terminal Repeats (LTRs). It is known that LTRs are sequences necessary for proper expression of viral genes; specific aptamers would inhibit the process. Studies obtained the aptamer with respective activity and its therapeutic effectiveness will be a subject of intensive examination [109].

\section{4) Delivery of therapeutic molecules to cells infected with viruses}

An interesting strategy for viral infections is the application of aptamers as specific messengers of oligonucleotides with therapeutic effect, such as small in- 
terfering RNA molecules. The use of the construct aptamer-siRNA would limit the specific therapy to the fraction of the target cells, selectively recognized by aptamer. Moreover, it could reduce the side effects accompanying other types of therapy. Liu et al. constructed fluorescein isothiocyanate (FITC)-conjugated RNA aptamer, HBs-A22, specific for a surface antigen HBsAg of HBV infected cells. They detected then infected HepG2.2.15 cells in fluorescence microscopy. They postulated to replace FITC particles with therapeutic agent in the future [110]. Zhou et al. went one step further. They designed a chimeric construct composed of anti-gp120 aptamer and the siRNA molecule directed against the mRNA of HIV-1 tat/rev protein in the model of CHO (Chinese Hamster Ovary cell line) cells. Their therapeutic potential was confirmed by decreased tat/rev mRNA expression in the qRT-PCR reaction. Proposed solution has been extremely beneficial, because anti-gp120 aptamer alone showed the inhibitory effect on virus infectivity. The therapeutic effect has been therefore strengthened [111]. Zhu et al. converted the anti-CD4 RNA aptamer into the DNA aptamer and combined it with the siRNA molecule directed against the mRNA of HIV-1 protease. Fluorescently labeled aptamer-siRNA conjugates up-take was confirmed by fluorescence microscopy, while inhibition effect was characterized by decrease in mRNA protease expression in CD4 $+\mathrm{T}$ cells transfected with pcDNA-HIV-PR plasmid as proved in qRT-PCR assay. Moreover, in comparison to RNA aptamers, their DNA counterparts seem to be more efficient in siRNA delivery [95].

\section{Delivery Systems Used in Nucleic Acid-Based Therapy}

One of the main challenges of nucleic acid-based therapy is the development of safe and effective administration systems that are able to overcome the main limitations of nucleic acids when they are administered in the body. Therefore, a fundamental aspect for the success of nucleic acid-based therapy is the availability of delivery systems capable of protecting the genetic material from degradation, facilitating its internalization in target cells, and releasing them intracellularly. The ideal delivery system depends on the target cells, the kind of nucleic acid to be delivered, and the duration of expression [113]. The delivery systems are classified into two large groups: viral and non-viral vectors.

\subsection{Viral Vectors}

Viral vectors are prepared from genetically modified viruses so that they are not able to replicate in the target cells, but they express the therapeutic gene they transport. Viral vectors allow high transfection efficiencies; however, they present important safety limitations due to the oncogenic and immunogenic potential (due to viral proteins). Another problem associated with viral vectors is the inability to transport large nucleic acids. Viruses used as delivery systems of genetic material include adenoviruses, adeno associated viruses (AAV), retroviruses, and lentiviruses among the most evaluated in clinical trials (Table 4). Other viruses, such as those derived from herpesvirus or poxvirus, have also been studied 
as possible viral vectors (Figure 19). The selection of the most suitable viral system in each case depends on different factors: the organ or the target cell, the ability to integrate the genetic material carried by the vector in the genome of the host cell, the duration of expression gene over time (short-term or long-term response), or the size of therapeutic nucleic acid [114].

\subsection{Non-Viral Vectors}

Non-viral vectors are safer, simpler, cheaper, and more reproducible systems. In addition, they do not present limitations regarding the size of the genetic material they can incorporate. Nevertheless, a disadvantage of non-viral systems is that their transfection efficiency is lower compared to viral vectors, although in recent years new non-viral systems have been developed with materials that exhibit higher transfection efficiencies. In fact, the number of clinical trials with products based on non-viral vectors has increased in the last decade, and those based on lipid nanocarriers (lipofection) are used in $4.1 \%$ of all trials (Gene Therapy Clinical Trials Worldwide, 2019). Non-viral systems can be defined as those physical or chemical methods that help in the process of transfer of exogenous genetic material to the cell, facilitating the entry and intracellular bioavailability thereof.

Table 4. Features of the most studied viral vectors [114].

\begin{tabular}{ccccc}
\hline & Retroviruses & Lentiviruses & Adenoviruses & $\begin{array}{c}\text { Adeno-associated } \\
\text { viruses }\end{array}$ \\
\hline Viral genome & RNA & RNA & DNA & DNA \\
Target cells & Dividing cells & $\begin{array}{c}\text { Dividing and } \\
\text { nondividing cells }\end{array}$ & $\begin{array}{c}\text { Dividing and } \\
\text { nondividing cells }\end{array}$ & $\begin{array}{c}\text { Dividing and } \\
\text { nondividing cells }\end{array}$ \\
$\begin{array}{c}\text { Integration in } \\
\text { the host genome }\end{array}$ & Yes & Yes & No & Yes \\
$\begin{array}{c}\text { Response } \\
\text { Size of the genetic } \\
\text { material to be } \\
\text { carried }\end{array}$ & Long-term & Long-term & Short-term & Long-term \\
\hline
\end{tabular}

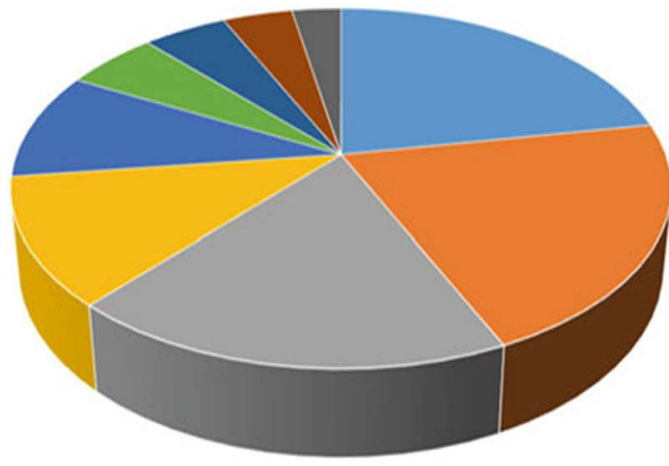

Adenovirus $(18.5 \%, \mathrm{n}=541)$

Retrovirus $(17.5 \%, \mathrm{n}=514)$

Naked/Plasmid DNA $(15.4 \%, n=452)$

Lentivirus $(9.5 \%, \mathrm{n}=\mathbf{2 7 8})$

Adeno-associated virus $(8.1 \%, \mathrm{n}=\mathbf{2 3 8})$

Vaccinia virus $(4.5 \%, \mathrm{n}=133)$

Lipofection $(4.1 \%, n=119)$

Herpes simplex virus $(3.4 \%, n=99)$

Poxvirus $(2.4 \%, n=71)$

Figure 19. Vectors used in clinical trials (Gene Therapy Clinical Trials Worldwide, 2019). 


\section{1) Physical methods}

Physical methods are based on the application of physical forces to temporarily alter the permeability of the cell membrane, allowing the genetic material to cross the cytoplasmic membrane and reach the interior of the cell (Table 5). It is important that there is a balance between the efficiency of cellular internalization and the damage exerted on the cell [115].

\section{2) Chemical carriers}

Chemical vectors are based on the use of different types of compounds capable of encapsulating or binding, electrostatically or covalently, the genetic material. In order to develop a suitable non-viral delivery system, the selected vector must have the capacity to enter the cell and to overcome different barriers maintaining the stability of the nucleic acid throughout the entire transfection process. Once within the cell, it must guarantee the proper intracellular distribution of genetic material. Chemical delivery systems or non-viral vectors are broadly categorized into inorganic, polymeric, lipidic, or peptidic particles. In

Table 5. Types of physical delivery systems main features [115].

\begin{tabular}{|c|c|c|}
\hline Method & Advantages & Limitations \\
\hline Needle injection & Simple & Low efficiency \\
\hline Direct needle injection on a specific tissue & Safe & Local inflammation \\
\hline $\begin{array}{l}\text { Hydrofection or hydrodynamic injection } \\
\text { Intravascular injection of high volumes of a } \\
\text { solution containing the nucleic acids }\end{array}$ & $\begin{array}{l}\text { High efficacy in the } \\
\text { Liver }\end{array}$ & Hemodynamic changes \\
\hline $\begin{array}{l}\text { Microinjection } \\
\text { Direct injection into host cell by microneedles }\end{array}$ & High efficiency & $\begin{array}{l}\text { Cell by cell administration } \\
\text { Time-consuming } \\
\text { Need of specialist }\end{array}$ \\
\hline $\begin{array}{l}\text { Biolistic injection or gene gun } \\
\text { Administration of metal microparticles at high } \\
\text { velocity }\end{array}$ & $\begin{array}{l}\text { Simple and fast } \\
\text { Reproducibility }\end{array}$ & $\begin{array}{l}\text { Low efficiency } \\
\text { Low tissue penetration } \\
\text { Cell damage } \\
\text { High cost }\end{array}$ \\
\hline & Noninvasive & \\
\hline Electroporation & Simple & Risk of tissue damage \\
\hline $\begin{array}{l}\text { Application of electric pulses that open pores on } \\
\text { cell membrane }\end{array}$ & $\begin{array}{l}\text { High efficiency } \\
\text { Low cost } \\
\text { Widely employed }\end{array}$ & $\begin{array}{l}\text { Surgery necessary to } \\
\text { target internal organs }\end{array}$ \\
\hline Sonoporation & Noninvasive & \\
\hline $\begin{array}{l}\text { Application of ultrasounds (combined with } \\
\text { microbubbles or nanocarriers) to permeabilize } \\
\text { temporally cell membrane }\end{array}$ & $\begin{array}{l}\text { Safe } \\
\text { Targeting to specific } \\
\text { tissues }\end{array}$ & $\begin{array}{l}\text { Low reproducibility } \\
\text { Tissue damage }\end{array}$ \\
\hline $\begin{array}{l}\text { Magnetofection } \\
\text { Application of external magnetic fields combined } \\
\text { with magnetic particles }\end{array}$ & $\begin{array}{l}\text { Noninvasive } \\
\text { Effective in primary } \\
\text { cells (difficult to } \\
\text { transfect) }\end{array}$ & $\begin{array}{l}\text { Effective only on surface } \\
\text { areas } \\
\text { Mainly applied in vitro }\end{array}$ \\
\hline $\begin{array}{l}\text { Optofection } \\
\text { Application of laser pulses combined with nucleic } \\
\text { acid complexes or nanoparticles }\end{array}$ & $\begin{array}{l}\text { Nucleic acids release } \\
\text { from endosomes }\end{array}$ & $\begin{array}{l}\text { Tissue damage } \\
\text { Inflammation } \\
\text { Restricted to single cells } \\
\text { or small areas }\end{array}$ \\
\hline
\end{tabular}


many cases, the combination of some of different kinds of chemical compounds is used in order to improve their profile of efficiency, cellular specificity, and safety, giving rise to hybrid systems [113].

\section{Inorganic particles}

Inorganic particles are nanostructured systems with different sizes, shapes, and porosity, designed to protect the genetic material from degradation and to escape from the reticuloendothelial system after its systemic administration. They can be composed of different elements, being used in gene therapy calcium phosphate, silica, gold, or magnetic compounds such as iron oxide. Cationic components are usually incorporated to the surface of the particle. An example of this type of system consists of combining iron oxide particles with PEI, which favors the condensation of nucleic acids, with polyethylene glycol (PEG), which favors the colloidal stability of the particles, and with cell penetration peptides, which favor cellular internalization. In the case of gold particles, nucleic acids are previously thiolated to covalently bound to the delivery system [116].

\section{Peptidic particles}

Some peptides are capable of condensing nucleic acids by themselves resulting in the formation of nanoparticulate systems. These include cationic peptides composed of short sequences of positively charged amino acids such as histidine, arginine, or lysine; in fact, poly-L-lysine is one of the peptide vectors with the highest transfection efficiency. Proteins of natural origin, such as collagen or albumin, are also used as peptide vectors [117].

\section{Polymeric particles}

The main component of these vectors is a cationic polymer that binds and condenses the genetic material, giving rise to the so-called polyplexes (Figure 20). Cationic polymers bind by electrostatic interactions the negatively charged genetic material, so that the nucleic acid is adsorbed to the surface of the nanoparticulate system or is encapsulated in its interior. In addition, these systems allow the incorporation of different ligands that improve the transfection efficiency in the target tissue [118].

\section{Lipidic particles}

Lipid-based systems are the most studied non-viral vectors at the clinical level. The main components of the lipid-based vectors are cationic lipids, formed by hydrophobic alkyl chains, linked through an intermediate binding structure to a polar group. The most used cationic lipids are 1,2-di-O-octadecenyl-3-trimethylammonium propane (DOTMA), 1,2-dioleoyloxy-3-trimethylammonium propane (DOTAP), 1,2-dimyristyloxypropyl-3-dimethyldhydroxy-ethyl-ammonium bromide (DMRIE), although derivatives of these lipids are also being studied in order to improve their efficacy and safety [119]. Thanks to their cationic nature, these lipids are able to condense and protect the genetic material, as well as to bind to the negative charges of the cell membranes. The main limitations of non-viral vectors based on cationic lipids are the low efficacy in vivo due to the fact that they are not stable and that they undergo rapid clearance, as well as the possibility of generating inflammatory or anti-inflammatory responses. 


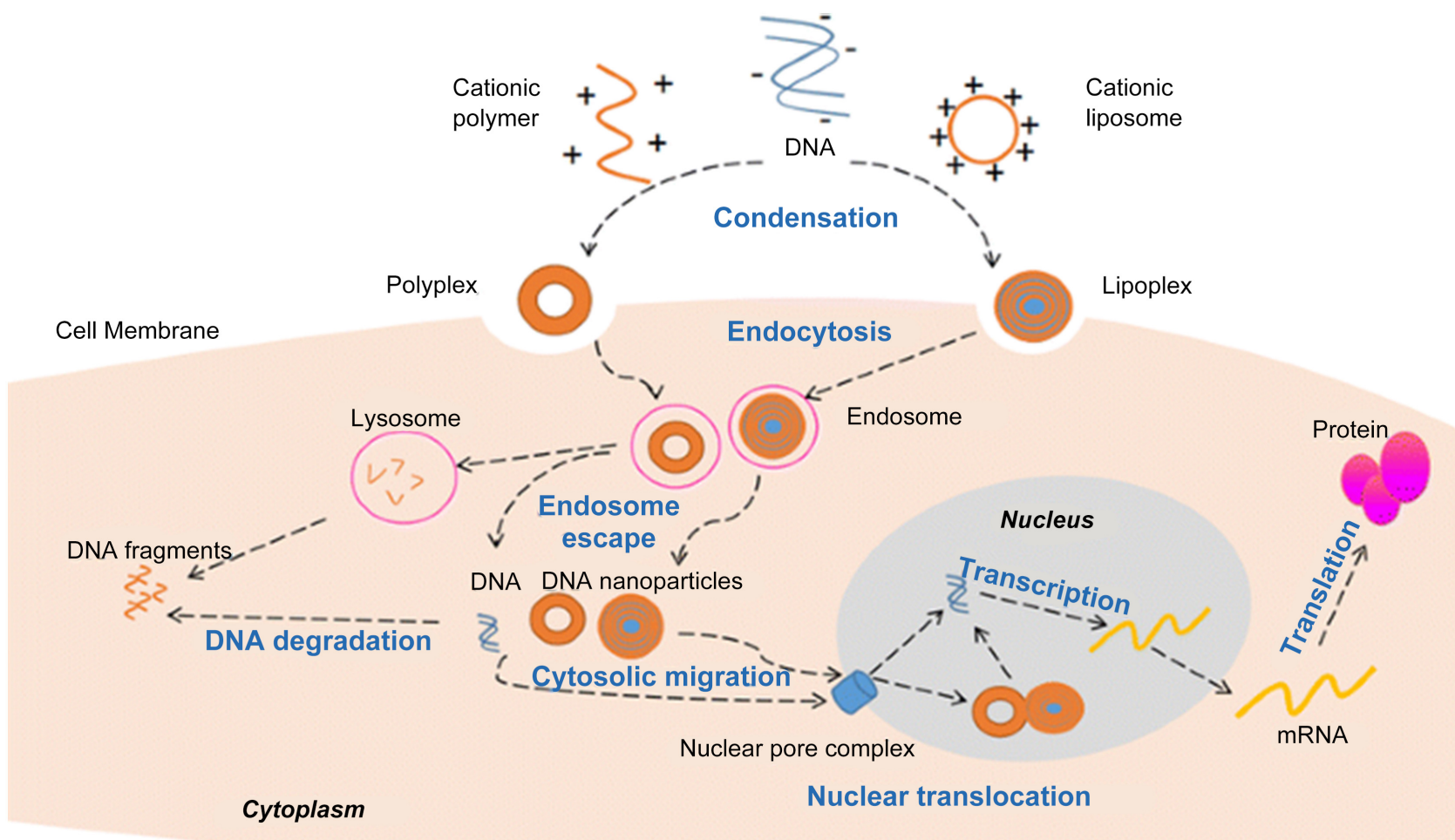

Figure 20. Basic mechanism of non-viral gene delivery via polyplex and lipoplex. DNA is condensed via interaction with a cationic polymer or encapsulated in a cationic liposome to form a polyplex or lipoplex and pass through the cell membrane via endocytosis.

Cationic lipids can be used by themselves to form complexes, known as lipoplexes, by mixing them directly with the negatively charged genetic material, but they are normally used to prepare colloidal systems that are then bound to the genetic material to obtain the lipoplexes (Figure 20) [120]. The colloidal lipid systems used mostly is liposomes [121]. Liposomes are spherical vesicles composed of one or more lipid bilayers surrounding an aqueous core, which show a size ranging from $20 \mathrm{~nm}$ to a few microns. Cationic liposomes are effective transfection systems in very varied types of cells in vitro and also in vivo after their local or systemic administration.

\section{Benefits of Nucleic Acid-Based Therapeutics}

A significant benefit of oligonucleotide-based therapeutics contrasted with conventional small molecule, peptide- or protein-based medications is the way that in many cases they can either be easily designed obeying simple Watson-Crick base pairing rules or isolated from libraries employing straight forward selection protocols like SELEX. Besides, since they address simple polymers of either riboor deoxynucleotide monomers their physicochemical and pharmaceutical properties are comparable regardless of size and sequence composition. Consequently, a given application plan may be applicable for a wide range of nucleic acid-based medications. In general, oligonucleotides show a binding affinity in the 
pico- to low nanomolar range and are highly specific for their desired targets. For molecules which exert their inhibitory effect through Watson-Crick base pairing, one or two mismatches over a stretch of approximately $20 \mathrm{nt}$ are commonly adequate to render them inactive or at least drastically reduce their activity. By a similar token, there are instances of aptamers varying by $3-4$ orders of magnitude in binding affinity for even highly related targets. Besides, nucleic acids are essentially non-immunogenic in contrast with peptide-or protein-based medications [9].

\section{Restrictions of Nucleic Acid-Based Therapeutics}

Notwithstanding the positive forecast of nucleic acid-based therapeutics over traditional drugs, there are certain limitations which need to be considered. The success of gene therapy may be compromised by two main challenges, the cost and reimbursement of the treatments, as well as the technological issues to ensure accessibility and quality of the treatments. Nucleic acid-based therapeutics have a high cost of development, production, product storage, and transportation, which lead to very high prices [118]. The stability of nucleic acids is fairly restricted with serum half-times in the range of seconds to minutes. To conquer this issue a variety of chemical modifications of either the base, ribose or phosphate backbone of the polymers are available [122]. Another issue of nucleic acid-based drugs is their fast renal clearance rate with half-times in the range of minutes. Again this hindrance can be relatively easy overcome enlarging the molecular weight of the polymers by complexation for instance with liposomes or by site-specific addition of polyethylene glycol (PEG), a procedure referred to as PEGylation [123]. These modifications together can raise both serum half-times and renal clearance rates in the order of days.

While stability and clearance issues are manageable, which likewise holds true for so called "off target effects", potential activation of the innate immune system or undesired side effects caused by saturation of endogenous pathways in the case of shRNAs, there remains the essentially unresolved and highly challenging problem of nucleic acid delivery [124]. The vast majority of the targets of potential oligonucleotide-based therapeutics are localized inside the cell. Consequently, as a prerequisite for efficacy they need to cross the membrane barrier. Next to viral vectors there are a variety of non-viral systems like cationic polymers, cationic liposomes, polymeric nanoparticles and cell-penetrating peptides which represent appealing ideas to bypass the problem of poor membrane permeability of these charged macromolecules [125]. Sometimes there is a streaming progress between local and systemic delivery; i.e., intranasal, intratracheal or topical. The oligomeric nucleic acids can be applied unmodified or chemically modified either naked or in combination with a carrier. Then again, whole plasmids or viral vectors encoding the desired sequence can be injected leading to a transient or stable endogenous expression of the corresponding oligonucleotide. 


\section{Conclusion and Perspectives}

Nucleic acid-based therapeutics have still many challenges to be overcome: the science is complex, treatment is technically difficult, and the regulatory approval process is necessarily different to that for conventional therapies. As a matter of fact, it has been considered as the most complex "drugs" at any point created. Efficacy, safety, and manufacturing issues are important challenges that must be faced. There are additional difficult questions about cost, accessibility, and social justice that will need answers once the methods are shown to be effective and safe. In this context it is not a surprise that only a single compound Vitravene has so far been approved by the FDA. Thus, the development of effective and safe delivery systems for therapeutic oligonucleotides is of utmost importance. Other than viral vectors, there is a highly diverse and constantly increasing number of non-viral systems evolving. Yet, at present even the most advanced systems either lack the efficiencies required for downstream drug development or do show a substantial degree of toxicity or both. Of the many factors which limit their utilization, cellular uptake of nucleic acids and particularly subsequent intracellular trafficking to reach the target site are the most important. Regardless of these existing obstacles, there are currently an expanding number of promising candidates entering clinical trials. The pace observed over the last few years in developing alternative delivery strategies fosters hope that in the near future an arsenal of different nucleic acid-based drugs might become available to battle viral infections.

\section{Conflicts of Interest}

The authors declare no conflicts of interest regarding the publication of this paper.

\section{References}

[1] Zamecnik, P.C. and Stephenson, M.L. (1978) Inhibition of Rous sarcoma Virus Replication and Cell Transformation by a Specific Oligodeoxynucleotide. Proceedings of the National Academy of Sciences of the United States of America, 75, 280-284. https://doi.org/10.1073/pnas.75.1.280

[2] Stec, W.J., Zon, G. and Egan, W. (1984) Automated Solid-Phase Synthesis, Separation, and Stereochemistry of Phosphorothioate Analogs of Oligodeoxyribonucleotides. Journal of the American Chemical Society, 106, 6077-6079. https://doi.org/10.1021/ja00332a054

[3] Elbashir, S.M., Harborth, J., Lendeckel, W., Yalcin, A., Weber, K. and Tuschl, T. (2001) Duplexes of 21-Nucleotide RNAs Mediate RNA Interference in Cultured Mammalian Cells. Nature, 411, 494-498. https://doi.org/10.1038/35078107

[4] Birmingham, A., et al. (2006) 3'UTR Seed Matches, but Not Overall Identity, Are Associated with RNAi Off-Targets. Nature Methods, 3, 199-204. https://doi.org/10.1038/nmeth854

[5] Hsu, C.Y.M. and Uludağ, H. (2012) Nucleic-Acid Based Gene Therapeutics: Delivery Challenges and Modular Design of Nonviral Gene Carriers and Expression Cassettes to Overcome Intracellular Barriers for Sustained Targeted Expression. 
Journal of Drug Targeting, 20, 301-328. https://doi.org/10.3109/1061186X.2012.655247

[6] Qureshi, A., Tantray, V.G., Kirmani, A.R. and Ahangar, A.G. (2018) A Review on Current Status of Antiviral siRNA. Reviews in Medical Virology, 28, e1976. https://doi.org/10.1002/rmv.1976

[7] Cann, A.J. (2008) Replication of Viruses. In: Mahy, B.W.J. and Van Regenmortel, M.H.V., Eds., Encyclopedia of Virology, Academic Press, Cambridge, MA, 406-412. https://doi.org/10.1016/B978-012374410-4.00486-6

[8] Arbuthnot, P. (2015) Gene Therapy for Respiratory Viral Infections. In: Arbuthnot, P., Gene Therapy for Viral Infections, Academic Press, Cambridge, MA, 281-297. https://doi.org/10.1016/B978-0-12-410518-8.00009-0

[9] Sridharan, K. and Gogtay, N.J. (2016) Therapeutic Nucleic Acids: Current Clinical Status. British Journal of Clinical Pharmacology, 82, 659-672. https://doi.org/10.1111/bcp.12987

[10] Summerton, J. and Weller, D. (1997) Morpholino Antisense Oligomers: Design, Preparation, and Properties. Antisense and Nucleic Acid Drug Development, 7, 187 195. https://doi.org/10.1089/oli.1.1997.7.187

[11] Monia, B.P., Johnston, J.F., Ecker, D.J., Zounes, M.A., Lima, W.F. and Freier, S.M. (1992) Selective Inhibition of Mutant Ha-ras mRNA Expression by Antisense Oligonucleotides. Journal of Biological Chemistry, 267, 19954-19962. https://doi.org/10.1016/S0021-9258(19)88650-7

[12] Monia, B.P., et al. (1993) Evaluation of 2'-Modified Oligonucleotides Containing 2'-Deoxy Gaps as Antisense Inhibitors of Gene Expression. Journal of Biological Chemistry, 268, 14514-14522. https://doi.org/10.1016/S0021-9258(19)85268-7

[13] Iversen, P.L. (2001) Phosphorodiamidate Morpholino Oligomers: Favorable Properties for Sequence-Specific Gene Inactivation. Current Opinion in Molecular Therapeutics, 3, 235-238.

[14] Petersen, M. and Wengel, J. (2003) LNA: A Versatile Tool for Therapeutics and Genomics. Trends in Biotechnology, 21, 74-81. https://doi.org/10.1016/S0167-7799(02)00038-0

[15] Saberi, F., Kamali, M., Najafi, A., Yazdanparast, A. and Moghaddam, M.M. (2016) Natural Antisense RNAs as mRNA Regulatory Elements in Bacteria: A Review on Function and Applications. Cellular \& Molecular Biology Letters, 21, Article No. 6. https://doi.org/10.1186/s11658-016-0007-z

[16] Chadwick, D.R. and Lever, A.M.L. (2000) Antisense RNA Sequences Targeting the 5' Leader Packaging Signal Region of Human Immunodeficiency Virus Type-1 Inhibits Viral Replication at Post-Transcriptional Stages of the Life Cycle. Gene Therapy, 7, 1362-1368. https://doi.org/10.1038/sj.gt.3301254

[17] Putlitz, J.Z., Wieland, S., Blum, H.E. and Wands, J.R. (1998) Antisense RNA Complementary to Hepatitis B Virus Specifically Inhibits Viral Replication. Gastroenterology, 115, 702-713. https://doi.org/10.1016/S0016-5085(98)70150-7

[18] Cramer, H., Okicki, J.R., Kuang, M. and Xu, Z. (2005) Targeted Therapy of Respiratory Syncytial Virus by 2-5A Antisense. Nucleosides, Nucleotides \& Nucleic Acids, 24, 497-501. https://doi.org/10.1081/NCN-200061780

[19] Le, T.K., Paris, C., Khan, K.S., Robson, F., Ng, W.-L. and Rocchi, P. (2020) Nucleic Acid-Based Technologies Targeting Coronaviruses. Trends in Biochemical Sciences, 46, 351-365. https://doi.org/10.1016/j.tibs.2020.11.010

[20] Geary, R.S., Henry, S.P. and Grillone, L.R. (2002) Fomivirsen. Clinical Pharmaco- 
kinetics, 41, 255-260. https://doi.org/10.2165/00003088-200241040-00002

[21] Levine, B.L., et al. (2006) Gene Transfer in Humans Using a Conditionally Replicating Lentiviral Vector. Proceedings of the National Academy of Sciences of the United States of America, 103, 17372-17377.

https://doi.org/10.1073/pnas.0608138103

[22] Witherell, G.W. (2001) ISIS-14803 (Isis Pharmaceuticals). Current Opinion in Investigational Drugs, 2, 1523-1529.

[23] Warren, T.K., et al. (2010) Advanced Antisense Therapies for Postexposure Protection against Lethal Filovirus Infections. Nature Medicine, 16, 991-994.

https://doi.org/10.1038/nm.2202

[24] Kruger, K., Grabowski, P.J., Zaug, A.J., Sands, J., Gottschling, D.E. and Cech, T.R. (1982) Self-Splicing RNA: Autoexcision and Autocyclization of the Ribosomal RNA Intervening Sequence of Tetrahymena. Cell, 31, 147-157. https://doi.org/10.1016/0092-8674(82)90414-7

[25] Chen, X., Li, N. and Ellington, A.D. (2007) Ribozyme Catalysis of Metabolism in the RNA World. Chemistry \& Biodiversity, 4, 633-655.

https://doi.org/10.1002/cbdv.200790055

[26] Benitez-Hess, M. and Alvarez-Salas, L. (2006) Utilization of Ribozymes as Antiviral Agents. Letters in Drug Design \& Discovery, 3, 390-404. https://doi.org/10.2174/157018006777805521

[27] Hertel, K.J., et al. (1992) Numbering System for the Hammerhead. Nucleic Acids Research, 20, 3252. https://doi.org/10.1093/nar/20.12.3252

[28] Butcher, S.E. and Burke, J.M. (1994) Structure-Mapping of the Hairpin Ribozyme: Magnesium-Dependent Folding and Evidence for Tertiary Interactions within the Ribozyme-Substrate Complex. Journal of Molecular Biology, 244, 52-63. https://doi.org/10.1006/jmbi.1994.1703

[29] Asha, K., Kumar, P., Sanicas, M., Meseko, C.A., Khanna, M. and Kumar, B. (2019) Advancements in Nucleic Acid Based Therapeutics against Respiratory Viral Infections. Journal of Clinical Medicine, 8, 6. https://doi.org/10.3390/jcm8010006

[30] Peracchi, A. (2004) Prospects for Antiviral Ribozymes and Deoxyribozymes. Reviews in Medical Virology, 14, 47-64. https://doi.org/10.1002/rmv.415

[31] Zakharchuk, A.N., Doronin, K.K., Karpov, V.A., Krougliak, V.A. and Naroditsky, B.S. (1995) The Fowl Adenovirus Type 1 (CELO) Virus-Associated RNA-Encoding Gene: A New Ribozyme-Expression Vector. Gene, 161, 189-193. https://doi.org/10.1016/0378-1119(95)00251-Z

[32] Lu, D., Chatterjee, S., Brar, D. and Wong Jr., K.K. (1994) Ribozyme-Mediated in Vitro Cleavage of Transcripts Arising from the Major Transforming Genes of $\mathrm{Hu}$ man Papillomavirus Type 16. Cancer Gene Therapy, 1, 267-277.

[33] Alvarez-Salas, L.M., Cullinan, A.E., Siwkowski, A., Hampel, A. and Dipaolo, J.A. (1998) Inhibition of HPV-16 E6/E7 Immortalization of Normal Keratinocytes by Hairpin Ribozymes. Proceedings of the National Academy of Sciences of the United States of America, 95, 1189-1194. https://doi.org/10.1073/pnas.95.3.1189

[34] Emerman, M. and Malim, M.H. (1998) HIV-1 Regulatory/Accessory Genes: Keys to Unraveling Viral and Host Cell Biology. Science, 280, 1880-1884.

https://doi.org/10.1126/science.280.5371.1880

[35] Mitsuyasu, R.T., et al. (2009) Phase 2 Gene Therapy Trial of an Anti-HIV Ribozyme in Autologous CD34+ Cells. Nature Medicine, 15, 285-292.

https://doi.org/10.1038/nm.1932 
[36] Ojwang, J.O., Hampel, A., Looney, D.J., Wong-Staal, F. and Rappaport, J. (1992) Inhibition of Human Immunodeficiency Virus Type 1 Expression by a Hairpin Ribozyme. Proceedings of the National Academy of Sciences of the United States of America, 89, 10802-10806. https://doi.org/10.1073/pnas.89.22.10802

[37] Nash, K.L., Alexander, G.J.M. and Lever, A.M.L. (2005) Inhibition of Hepatitis B Virus by Lentiviral Vector Delivered Antisense RNA and Hammerhead Ribozymes. Journal of Viral Hepatitis, 12, 346-356. https://doi.org/10.1111/j.1365-2893.2005.00612.x

[38] Beck, J. and Nassal, M. (1995) Efficient Hammerhead Ribozyme-Mediated Cleavage of the Structured Heapatitis B Virus Encapsidation Signal in Vitro and in Cell Extracts, but Not in Intact Cells. Nucleic Acids Research, 23, 4954-4962. https://doi.org/10.1093/nar/23.24.4954

[39] Trepanier, J.B., Tanner, J.E. and Alfieri, C. (2006) Oligonucleotide-Based Therapeutic Options against Hepatitis C Virus Infection. Antiviral Therapy, 11, 273-287.

[40] Lévesque, M.V., Lévesque, D., Brière, F.P. and Perreault, J.-P. (2010) Investigating a New Generation of Ribozymes in Order to Target HCV. PLOS ONE, 5, e9627. https://doi.org/10.1371/journal.pone.0009627

[41] Breaker, R.R. (1997) DNA Enzymes. Nature Biotechnology, 15, 427-431. https://doi.org/10.1038/nbt0597-427

[42] Dass, C.R., Saravolac, E.G., Li, Y. and Sun, L.-Q. (2002) Cellular Uptake, Distribution, and Stability of 10-23 Deoxyribozymes. Antisense and Nucleic Acid Drug Development, 12, 289-299. https://doi.org/10.1089/108729002761381276

[43] Warashina, M., Kuwabara, T., Nakamatsu, Y. and Taira, K. (1999) Extremely High and Specific Activity of DNA Enzymes in Cells with a Philadelphia Chromosome. Chemistry \& Biology, 6, 237-250. https://doi.org/10.1016/S1074-5521(99)80039-8

[44] Kumar, B., Kumar, P., Rajput, R., Saxena, L., Daga, M.K. and Khanna, M. (2013) Sequence-Specific Cleavage of BM2 Gene Transcript of Influenza B Virus by 10-23 Catalytic Motif Containing DNA Enzymes Significantly Inhibits Viral RNA Translation and Replication. Nucleic Acid Therapeutics, 23, 355-362. https://doi.org/10.1089/nat.2013.0432

[45] Zhou, J., et al. (2007) Inhibition of Respiratory Syncytial Virus of Subgroups A and B Using Deoxyribozyme DZ1133 in Mice. Virus Research, 130, 241-248. https://doi.org/10.1016/j.virusres.2007.06.017

[46] Wu, S., et al. (2007) An Efficient RNA-Cleaving DNA Enzyme Can Specifically Target the 5'-Untranslated Region of Severe Acute Respiratory Syndrome Associated Coronavirus (SARS-CoV). The Journal of Gene Medicine, 9, 1080-1086. https://doi.org/10.1002/jgm.1111

[47] Graham, I.R., Beattie, S.G., Hill, V.J. and Dickson, G. (2001) Oligonucleotide-Based Gene Correction Strategies: Applications to Neuromuscular and Cardiovascular Diseases. Croatian Medical Journal, 42, 467-472.

[48] Yoon, K., Cole-Strauss, A. and Kmiec, E.B. (1996) Targeted Gene Correction of Episomal DNA in Mammalian Cells Mediated by a Chimeric RNA.DNA Oligonucleotide. Proceedings of the National Academy of Sciences of the United States of America, 93, 2071-2076. https://doi.org/10.1073/pnas.93.5.2071

[49] Fukushima, A., et al. (2009) Development of a Chimeric DNA-RNA Hammerhead Ribozyme Targeting SARS Virus. Intervirology, 52, 92-99. https://doi.org/10.1159/000215946

[50] Fire, A., Xu, S., Montgomery, M.K., Kostas, S.A., Driver, S.E. and Mello, C.C. (1998) Potent and Specific Genetic Interference by Double-Stranded RNA in Caenorhabdi- 
tis elegans. Nature, 391, 806-811. https://doi.org/10.1038/35888

[51] Torrecilla, J., Rodríguez-Gascón, A., Solinís, M.Á. and del Pozo-Rodríguez, A. (2014) Lipid Nanoparticles as Carriers for RNAi Against Viral Infections: Current Status and Future Perspectives. BioMed Research International, 2014, Article ID: 161794. https://doi.org/10.1155/2014/161794

[52] Ha, M. and Kim, V.N. (2014) Regulation of microRNA Biogenesis. Nature Reviews Molecular Cell Biology, 15, 509-524. https://doi.org/10.1038/nrm3838

[53] Parrish, S., Fleenor, J., Xu, S., Mello, C. and Fire, A. (2000) Functional Anatomy of a dsRNA Trigger: Differential Requirement for the Two Trigger Strands in RNA Interference. Molecular Cell, 6, 1077-1087. https://doi.org/10.1016/S1097-2765(00)00106-4

[54] Rozenblum, G.T., Lopez, V.G., Vitullo, A.D. and Radrizzani, M. (2016) Aptamers: Current Challenges and Future Prospects. Expert Opinion on Drug Discovery, 11, 127-135. https://doi.org/10.1517/17460441.2016.1126244

[55] Chiu, Y.L. and Rana, T.M. (2003) siRNA Function in RNAi: A Chemical Modification Analysis. $R N A, 9,1034-1048$. https://doi.org/10.1261/rna.5103703

[56] Harborth, J., et al. (2003) Sequence, Chemical, and Structural Variation of Small Interfering RNAs and Short Hairpin RNAs and the Effect on Mammalian Gene Silencing. Antisense and Nucleic Acid Drug Development, 13, 83-105. https://doi.org/10.1089/108729003321629638

[57] Hall, A.H.S., Wan, J., Shaughnessy, E.E., Shaw, B.R. and Alexander, K.A. (2004) RNA Interference Using Boranophosphate siRNAs: Structure-Activity Relationships. Nucleic Acids Research, 32, 5991-6000. https://doi.org/10.1093/nar/gkh936

[58] O'Keefe, E.P. (2013) siRNAs and shRNAs: Tools for Protein Knockdown by Gene Silencing. Mater Methods, 3, 197. https://doi.org/10.13070/mm.cn.3.197

[59] Filipowicz, W. (2005) RNAi: The Nuts and Bolts of the RISC Machine. Cell, 122, 17-20. https://doi.org/10.1016/j.cell.2005.06.023

[60] Zarnore, P.D. and Haley, B. (2005) The Big World of Small RNAs. Science, 309, 1519-1524. https://doi.org/10.1126/science.1111444

[61] Ketzinel-Gilad, M., Shaul, Y. and Galun, E. (2006) RNA Interference for Antiviral Therapy. The Journal of Gene Medicine, 8, 933-950. https://doi.org/10.1002/jgm.929

[62] Ge, Q., et al. (2003) RNA Interference of Influenza Virus Production by Directly Targeting mRNA for Degradation and Indirectly Inhibiting all Viral RNA Transcription. Proceedings of the National Academy of Sciences of the United States of America, 100, 2718-2723. https://doi.org/10.1073/pnas.0437841100

[63] Song, E., et al. (2003) RNA Interference Targeting Fas Protects Mice from Fulminant Hepatitis. Nature Medicine, 9, 347-351. https://doi.org/10.1038/nm828

[64] Kapadia, S.B., Brideau-Andersen, A. and Chisari, F.V. (2003) Interference of Hepatitis C Virus RNA Replication by Short Interfering RNAs. Proceedings of the National Academy of Sciences of the United States of America, 100, 2014-2018. https://doi.org/10.1073/pnas.252783999

[65] Valdes, V.J., Sampieri, A., Sepulveda, J. and Vaca, L. (2003) Using Double-Stranded RNA to Prevent Viral Infections in Vitro and in Vivo by Recombinant Baculoviruses. Journal of Biological Chemistry, 278, 19317-19324. https://doi.org/10.1074/jbc.M212039200

[66] Qin, X.-F., An, D.S., Chen, I.S.Y. and Baltimore, D. (2003) Inhibiting HIV-1 Infection in Human $\mathrm{T}$ Cells by Lentiviral-Mediated Delivery of Small Interfering RNA 
against CCR5. Proceedings of the National Academy of Sciences of the United States of America, 100, 183-188. https://doi.org/10.1073/pnas.232688199

[67] Bitko, V. and Barik, S. (2001) Phenotypic Silencing of Cytoplasmic Genes Using Sequence-Specific Double-Stranded Short Interfering RNA and Its Application in the Reverse Genetics of Wild Type Negative-Strand RNA Viruses. BMC Microbiology, 1, Article No. 34. https://doi.org/10.1186/1471-2180-1-34

[68] Zhang, Y., et al. (2004) Silencing SARS-CoV Spike Protein Expression in Cultured Cells by RNA Interference. FEBS Letters, 560, 141-146. https://doi.org/10.1016/S0014-5793(04)00087-0

[69] Hu, W.-Y., Myers, C.P., Kilzer, J.M., Pfaff, S.L. and Bushman, F.D. (2002) Inhibition of Retroviral Pathogenesis by RNA Interference. Current Biology, 12, 1301-1311. https://doi.org/10.1016/S0960-9822(02)00975-2

[70] Park, W., et al. (2002) Prevention of HIV-1 Infection in Human Peripheral Blood Mononuclear Cells by Specific RNA Interference. Nucleic Acids Research, 30, 48304835. https://doi.org/10.1093/nar/gkf627

[71] McCown, M., Diamond, M.S. and Pekosz, A. (2003) The Utility of siRNA Transcripts Produced by RNA Polymerase I in Down Regulating Viral Gene Expression and Replication of Negative- and Positive-Strand RNA Viruses. Virology, 313, 514-524. https://doi.org/10.1016/S0042-6822(03)00341-6

[72] Hamasaki, K., Nakao, K., Matsumoto, K., Ichikawa, T., Ishikawa, H. and Eguchi, K. (2003) Short Interfering RNA-Directed Inhibition of Hepatitis B Virus Replication. FEBS Letters, 543, 51-54. https://doi.org/10.1016/S0014-5793(03)00400-9

[73] McCaffrey, A.P., Nakai, H., Pandey, K., Huang, Z., Salazar, F.H., Xu, H., Wieland, S.F., Marion, P.L. and Kay, M.A. (2003) Inhibition of Hepatitis B Virus in Mice by RNA Interference. Nature Biotechnology, 21, 639-644. https://doi.org/10.1038/nbt824

[74] Li, X.-P., Li, G., Peng, Y., Kung, H. and Lin, M.C. (2004) Suppression of Epstein-Barr Virus-Encoded Latent Membrane Protein-1 by RNA Interference Inhibits the Metastatic Potential of Nasopharyngeal Carcinoma Cells. Biochemical and Biophysical Research Communications, 315, 212-218. https://doi.org/10.1016/j.bbrc.2004.01.045

[75] Déctor, M.A., Romero, P., López, S. and Arias, C.F. (2002) Rotavirus Gene Silencing by Small Interfering RNAs. EMBO Reports, 3, 1175-1180.

https://doi.org/10.1093/embo-reports/kvf234

[76] Barik, S. (2004) Control of Nonsegmented Negative-Strand RNA Virus Replication by siRNA. Virus Research, 102, 27-35. https://doi.org/10.1016/j.virusres.2004.01.012

[77] Randall, G., Grakoui, A. and Rice, C.M. (2003) Clearance of Replicating Hepatitis C Virus Replicon RNAs in Cell Culture by Small Interfering RNAs. Proceedings of the National Academy of Sciences of the United States of America, 100, 235-240. https://doi.org/10.1073/pnas.0235524100

[78] Li, W.-X., et al. (2004) Interferon Antagonist Proteins of Influenza and Vaccinia Viruses Are Suppressors of RNA Silencing. Proceedings of the National Academy of Sciences of the United States of America, 101, 1350-1355.

https://doi.org/10.1073/pnas.0308308100

[79] Patel, A., Bah, M.A. and Weiner, D.B. (2020) In Vivo Delivery of Nucleic Acid-Encoded Monoclonal Antibodies. BioDrugs, 34, 273-293. https://doi.org/10.1007/s40259-020-00412-3

[80] Flingai, S., et al. (2015) Protection against Dengue Disease by Synthetic Nucleic Acid Antibody Prophylaxis/Immunotherapy. Scientific Reports, 5, Article No. 12616. 
https://doi.org/10.1038/srep12616

[81] Yamazaki, T., et al. (2011) Passive Immune-Prophylaxis against Influenza Virus Infection by the Expression of Neutralizing Anti-Hemagglutinin Monoclonal Antibodies from Plasmids. Japanese Journal of Infectious Diseases, 64, 40-49.

[82] Andrews, C.D., et al. (2017) In Vivo Production of Monoclonal Antibodies by Gene Transfer via Electroporation Protects against Lethal Influenza and Ebola Infections. Molecular Therapy-Methods \& Clinical Development, 7, 74-82. https://doi.org/10.1016/j.omtm.2017.09.003

[83] Gershoni, J.M. (2008) Molecular Decoys: Antidotes, Therapeutics and Immunomodulators. Current Opinion in Biotechnology, 19, 644-651.

https://doi.org/10.1016/j.copbio.2008.10.001

[84] Bohjanen, P.R., Colvin, R.A., Puttaraju, M., Been, M.D. and Garcia-Blanco, M.A. (1996) A Small Circular TAR RNA Decoy Specifically Inhibits Tat-Activated HIV-1 Transcription. Nucleic Acids Research, 24, 3733-3738.

https://doi.org/10.1093/nar/24.19.3733

[85] Bahner, I., Kearns, K., Hao, Q.L., Smogorzewska, E.M. and Kohn, D.B. (1996) Transduction of Human CD34+ Hematopoietic Progenitor Cells by a Retroviral Vector Expressing an RRE Decoy Inhibits Human Immunodeficiency Virus Type 1 Replication in Myelomonocytic Cells Produced in Long-Term Culture. Journal of Virology, 70, 4352-4360. https://doi.org/10.1128/jvi.70.7.4352-4360.1996

[86] Anderson, J., et al. (2007) Safety and Efficacy of a Lentiviral Vector Containing Three Anti-HIV Genes-CCR5 Ribozyme, Tat-rev siRNA, and TAR Decoy-In SCIDhu Mouse-Derived T Cells. Molecular Therapy, 15, 1182-1188. https://doi.org/10.1038/sj.mt.6300157

[87] Stojanovic, T., Wagner, A.H., Schöndube, F.A. and Hecker, M. (2012) Pre-Transplant Therapy in Experimental Heart Transplantation. In: Moffatt-Bruce, S., Ed., Cardiac Transplantation, IntechOpen, London. https://doi.org/10.5772/28531

[88] Ellington, A.D. and Szostak, J.W. (1990) In Vitro Selection of RNA Molecules That Bind Specific Ligands. Nature, 346, 818-822. https://doi.org/10.1038/346818a0

[89] Cerchia, L. and De Franciscis, V. (2006) Noncoding RNAs in Cancer Medicine. Journal of Biomedicine and Biotechnology, 2006, Article ID: 073104. https://doi.org/10.1155/JBB/2006/73104

[90] Nimjee, S.M., Rusconi, C.P. and Sullenger, B.A. (2005) Aptamers: An Emerging Class of Therapeutics. Annual Review of Medicine, 56, 555-583. https://doi.org/10.1146/annurev.med.56.062904.144915

[91] Ospina-Villa, J.D., Zamorano-Carrillo, A., Castañón-Sánchez, C.A., Ramírez-Moreno, E. and Marchat, L.A. (2016) Aptamers as a Promising Approach for the Control of Parasitic Diseases. The Brazilian Journal of Infectious Diseases, 20, 610-618. https://doi.org/10.1016/j.bjid.2016.08.011

[92] Tuerk, C. and Gold, L. (1990) Systematic Evolution of Ligands by Exponential Enrichment: RNA Ligands to Bacteriophage T4 DNA Polymerase. Science, 249, 505-510. https://doi.org/10.1126/science.2200121

[93] Patel, D.J. and Suri, A.K. (2000) Structure, Recognition and Discrimination in RNA Aptamer Complexes with Cofactors, Amino Acids, Drugs and Aminoglycoside Antibiotics. Reviews in Molecular Biotechnology, 74, 39-60. https://doi.org/10.1016/S1389-0352(99)00003-3

[94] Kim, T.-H. and Lee, S.-W. (2021) Aptamers for Anti-Viral Therapeutics and Diagnostics. International Journal of Molecular Sciences, 22, 4168.

https://doi.org/10.3390/ijms22084168 
[95] Zhu, Q., Shibata, T., Kabashima, T. and Kai, M. (2012) Inhibition of HIV-1 Protease Expression in T Cells Owing to DNA Aptamer-Mediated Specific Delivery of siRNA. European Journal of Medicinal Chemistry, 56, 396-399. https://doi.org/10.1016/j.ejmech.2012.07.045

[96] Dey, A.K., Griffiths, C., Lea, S.M. and James, W. (2005) Structural Characterization of an Anti-gp120 RNA Aptamer That Neutralizes R5 Strains of HIV-1. RNA, 11, 873-884. https://doi.org/10.1261/rna.7205405

[97] Cohen, C., et al. (2008) An Aptamer That Neutralizes R5 Strains of HIV-1 Binds to Core Residues of gp120 in the CCR5 Binding Site. Virology, 381, 46-54. https://doi.org/10.1016/j.virol.2008.08.025

[98] Chen, F., Hu, Y., Li, D., Chen, H. and Zhang, X.-L. (2009) CS-SELEX Generates High-Affinity ssDNA Aptamers as Molecular Probes for Hepatitis C Virus Envelope Glycoprotein E2. PLoS ONE, 4, e8142. https://doi.org/10.1371/journal.pone.0008142

[99] Jeon, S.H., Kayhan, B., Ben-Yedidia, T. and Arnon, R. (2004) A DNA Aptamer Prevents Influenza Infection by Blocking the Receptor Binding Region of the Viral Hemagglutinin. Journal of Biological Chemistry, 279, 48410-48419. https://doi.org/10.1074/jbc.M409059200

[100] Wang, J., Jiang, H. and Liu, F. (2000) In Vitro Selection of Novel RNA Ligands That Bind Human Cytomegalovirus and Block Viral Infection. RNA, 6, 571-583. https://doi.org/10.1017/S1355838200992215

[101] Gopinath, S.C.B., Hayashi, K. and Kumar, P.K.R. (2012) Aptamer That Binds to the gD Protein of Herpes Simplex Virus 1 and Efficiently Inhibits Viral Entry. Journal of Virology, 86, 6732-6744. https://doi.org/10.1128/JVI.00377-12

[102] Biroccio, A., Hamm, J., Incitti, I., De Francesco, R. and Tomei, L. (2002) Selection of RNA Aptamers That Are Specific and High-Affinity Ligands of the Hepatitis C Virus RNA-Dependent RNA Polymerase. Journal of Virology, 76, 3688-3696. https://doi.org/10.1128/JVI.76.8.3688-3696.2002

[103] Feng, H., Beck, J., Nassal, M. and Hu, K. (2011) A SELEX-Screened Aptamer of Human Hepatitis B Virus RNA Encapsidation Signal Suppresses Viral Replication. PLoS ONE, 6, e27862. https://doi.org/10.1371/journal.pone.0027862

[104] Kanai, A., Tanabe, K. and Kohara, M. (1995) Poly(U) Binding Activity of Hepatitis C Virus NS3 Protein, a Putative RNA Helicase. FEBS Letters, 376, 221-224. https://doi.org/10.1016/0014-5793(95)01283-X

[105] Umehara, T., et al. (2004) Designing and Analysis of a Potent Bi-Functional Aptamers That Inhibit Protease and Helicase Activities of HCV NS3. Nucleic Acids Symposium Series, 48, 195-196. https://doi.org/10.1093/nass/48.1.195

[106] Jang, K.J., Lee, N.-R., Yeo, W.-S., Jeong, Y.-J. and Kim, D.-E. (2008) Isolation of Inhibitory RNA Aptamers against Severe Acute Respiratory Syndrome (SARS) Coronavirus NTPase/Helicase. Biochemical and Biophysical Research Communications, 366, 738-744. https://doi.org/10.1016/j.bbrc.2007.12.020

[107] Konno, K., Fujita, S., Iizuka, M., Nishikawa, S., Hasegawa, T. and Fukuda, K. (2008) Isolation and Characterization of RNA Aptamers Specific for the HCV Minus-IRES Domain I. Nucleic Acids Symposium Series, 52, 493-494. https://doi.org/10.1093/nass/nrn250

[108] Romero-López, C., Berzal-Herranz, B., Gómez, J. and Berzal-Herranz, A. (2012) An Engineered Inhibitor RNA That Efficiently Interferes with Hepatitis C Virus Translation and Replication. Antiviral Research, 94, 131-138. https://doi.org/10.1016/j.antiviral.2012.02.015 
[109] Srisawat, C. and Engelke, D.R. (2010) Selection of RNA Aptamers That Bind HIV-1 LTR DNA Duplexes: Strand Invaders. Nucleic Acids Research, 38, 8306-8315. https://doi.org/10.1093/nar/gkq696

[110] Liu, J., et al. (2010) Development of HBsAg-Binding Aptamers That Bind HepG2. 2.15 Cells via HBV Surface Antigen. Virologica Sinica, 25, 27-35. https://doi.org/10.1007/s12250-010-3091-7

[111] Zhou, J., Li, H., Li, S., Zaia, J. and Rossi, J.J. (2008) Novel Dual Inhibitory Function Aptamer-siRNA Delivery System for HIV-1 Therapy. Molecular Therapy, 16, 1481 1489. https://doi.org/10.1038/mt.2008.92

[112] Afrasiabi, S., Pourhajibagher, M., Raoofian, R., Tabarzad, M. and Bahador, A. (2020) Therapeutic Applications of Nucleic Acid Aptamers in Microbial Infections. Journal of Biomedical Science, 27, Article No. 6. https://doi.org/10.1186/s12929-019-0611-0

[113] Ramamoorth, M. and Narvekar, A. (2015) Non Viral Vectors in Gene Therapy-An Overview. Journal of Clinical and Diagnostic Research, 9, GE01-GE06. https://doi.org/10.7860/JCDR/2015/10443.5394

[114] del Pozo-Rodríguez, A., Solinís, M.Á. and Rodríguez-Gascón, A. (2016) Applications of Lipid Nanoparticles in Gene Therapy. European Journal of Pharmaceutics and Biopharmaceutics, 109, 184-193. https://doi.org/10.1016/j.ejpb.2016.10.016

[115] Herrero, M.J., Sendra, L., Miguel, A. and Aliño, S.F. (2017) Physical Methods of Gene Delivery. In: Brunetti-Pierri, N., Eds., Safety and Efficacy of Gene-Based Therapeutics for Inherited Disorders, Springer, Cham, 113-135. https://doi.org/10.1007/978-3-319-53457-2 6

[116] Hu, Y., Wen, C., Song, L., Zhao, N. and Xu, F.-J. (2017) Multifunctional HeteroNanostructures of Hydroxyl-Rich Polycation Wrapped Cellulose-Gold Hybrids for Combined Cancer Therapy. Journal of Controlled Release, 255, 154-163. https://doi.org/10.1016/j.jconrel.2017.04.001

[117] Look, J., et al. (2015) Ligand-Modified Human Serum Albumin Nanoparticles for Enhanced Gene Delivery. Molecular Pharmaceutics, 12, 3202-3213. https://doi.org/10.1021/acs.molpharmaceut.5b00153

[118] Sung, Y.K. and Kim, S.W. (2019) Recent Advances in the Development of Gene Delivery Systems. Biomaterials Research, 23, Article No. 8. https://doi.org/10.1186/s40824-019-0156-Z

[119] Sasaki, S. and Guo, S. (2018) Nucleic Acid Therapies for Cystic Fibrosis. Nucleic Acid Therapeutics, 28, 1-9. https://doi.org/10.1089/nat.2017.0696

[120] Wu, P., et al. (2018) Non-Viral Gene Delivery Systems for Tissue Repair and Regeneration. Journal of Translational Medicine, 16, Article No. 29. https://doi.org/10.1186/s12967-018-1402-1

[121] del Pozo-Rodríguez, A., et al. (2019) Gene Therapy. In: Silva, A.C., Moreira, J.N., Lobo, J.M.S. and Almeida, H., Eds., Current Applications of Pharmaceutical Biotechnology. Advances in Biochemical Engineering/ Biotechnology, Vol. 171, Springer, Cham, 321-368. https://doi.org/10.1007/10 2019 109

[122] Jens, K. (2003) Antisense Technologies Improvement through Novel Chemical Modification. European Journal of Biochemistry, 270, 1628-1644.

https://doi.org/10.1046/j.1432-1033.2003.03555.x

[123] Ryan, S.M., Mantovani, G., Wang, X., Haddleton, D.M. and Brayden, D.J. (2008) Advances in PEGylation of Important Biotech Molecules: Delivery Aspects. Expert Opinion on Drug Delivery, 5, 371-383. https://doi.org/10.1517/17425247.5.4.371

[124] Jackson, A.L. and Linsley, P.S. (2010) Recognizing and Avoiding siRNA Off-Target 
Effects for Target Identification and Therapeutic Application. Nature Reviews Drug Discovery, 9, 57-67. https://doi.org/10.1038/nrd3010

[125] Laufer, S.D. and Restle, T. (2008) Peptide-Mediated Cellular Delivery of Oligonucleotide-Based Therapeutics in Vitro: Quantitative Evaluation of Overall Efficacy Employing Easy to Handle Reporter Systems. Current Pharmaceutical Design, 14, 3637 3655. https://doi.org/10.2174/138161208786898806 